\title{
One-Step Synthesis of Triphenylphosphonium Salts from (Het)arylmethyl Alcohols
}

Petrakis N. Chalikidi, ${ }^{*} \uparrow$ Taimuraz T. Magkoev, $\uparrow$ Andrey V. Gutnov, $\dagger, \#$ Oleg P. Demidov, $\$$ Maxim G. Uchuskin, ${ }^{*}, \S$ Igor V. Trushkov,\|, $\perp$ Vladimir T. Abaev†, $\$$

$\dagger$ North-Ossetian State University, Vatutina st. 46, Vladikavkaz, 362025, Russian Federation, email: chalikidi@gmail.com

\# Chiroblock GmbH, Andresenstr. 1a, Wolfen, 06766, Germany

\$ North Caucasus Federal University, Pushkin st. 1, Stavropol, 355009, Russian Federation

|| N.D. Zelinsky Institute of Organic Chemistry Russian Academy of Sciences, Leninsky pr. 47, Moscow, 119991, Russian Federation

$\perp$ D. Rogachev National Medical Research Center of Pediatric Hematology, Oncology and Immunology, Samory Mashela st. 1, Moscow, 117997, Russian Federation

$\S$ Perm State University, Bukireva st. 15, Perm, 614990, Russian Federation, e-mail: $\underline{\text { mu@ @su.ru }}$

Table of Contents

Copies of NMR spectra 
2a, ${ }^{1} \mathrm{H}$ NMR (400 MHz, DMSO)

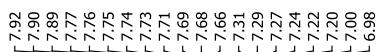

กิซ

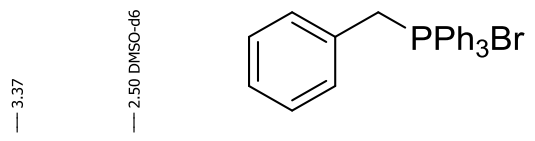

2a

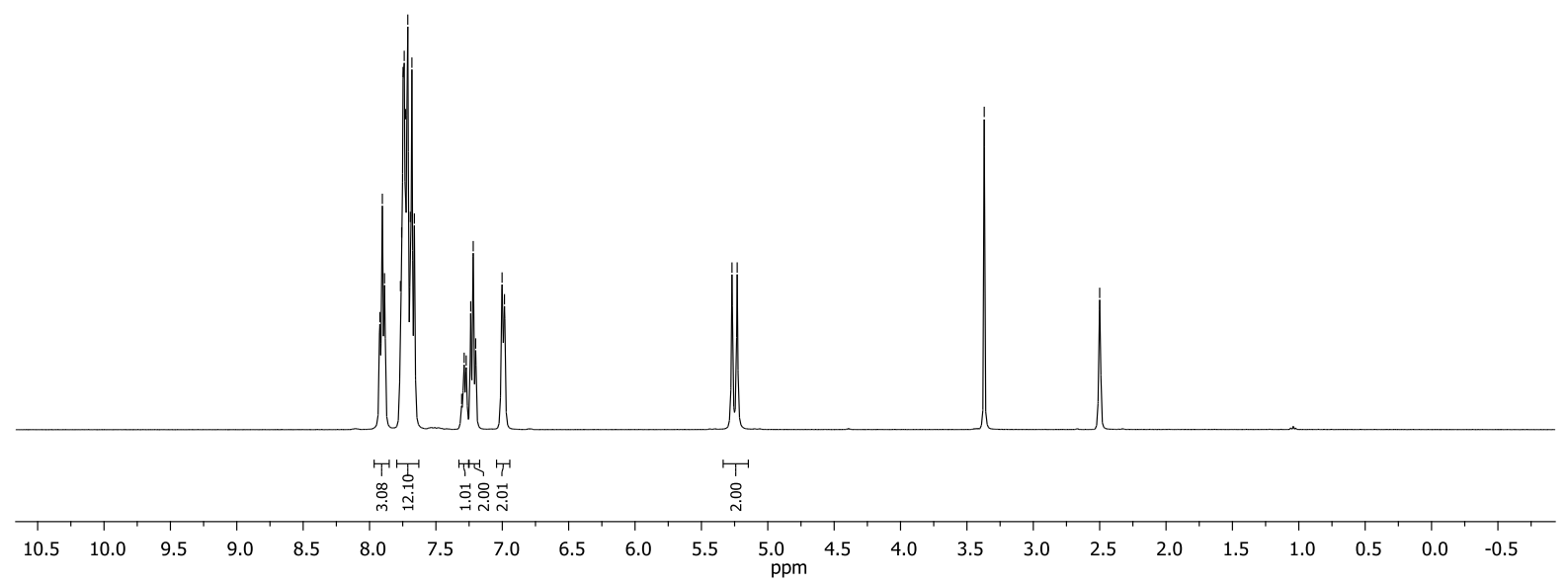

2a, ${ }^{13} \mathrm{C}\left\{{ }^{1} \mathrm{H}\right\}$ NMR (100 MHz, DMSO)

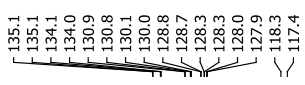

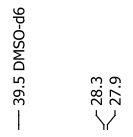
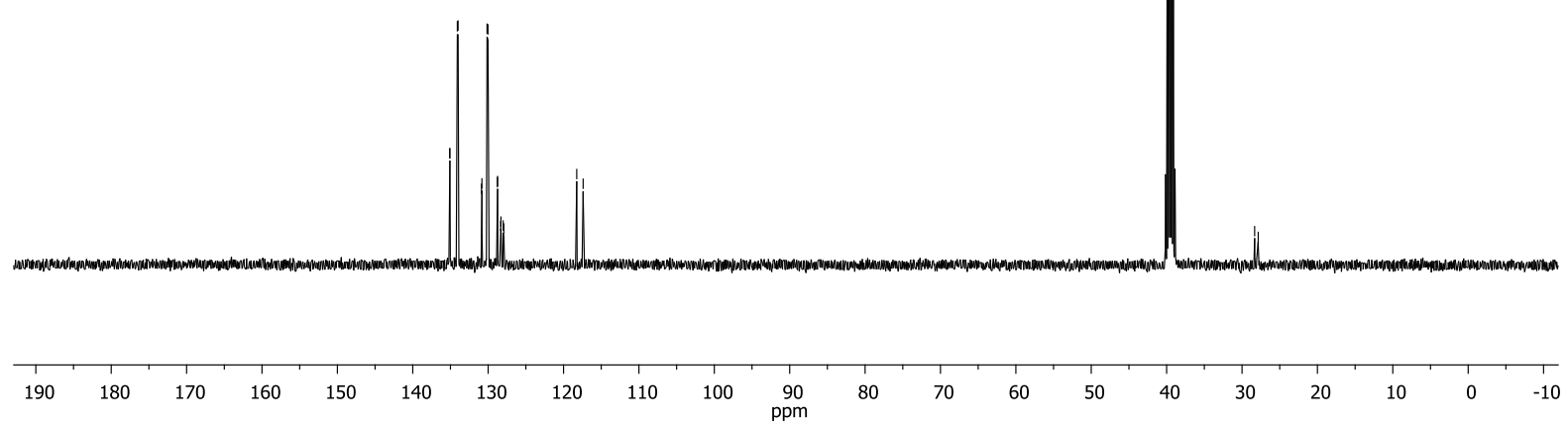

S2 
2b, ${ }^{1} \mathrm{H}$ NMR (400 MHz, DMSO)
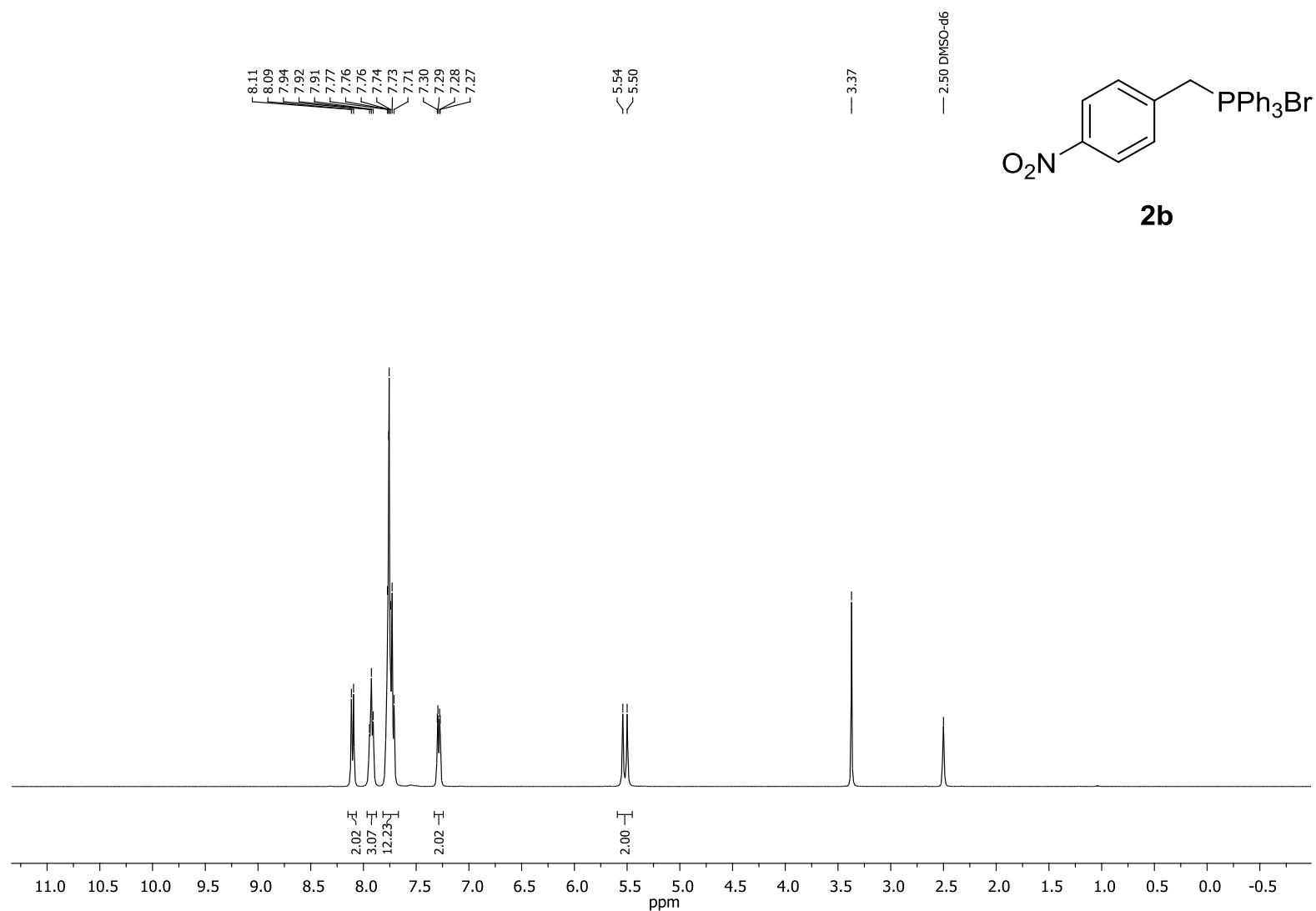

2b, ${ }^{13} \mathrm{C}\left\{{ }^{1} \mathrm{H}\right\}$ NMR (100 MHz, DMSO)

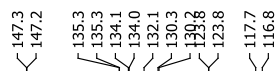
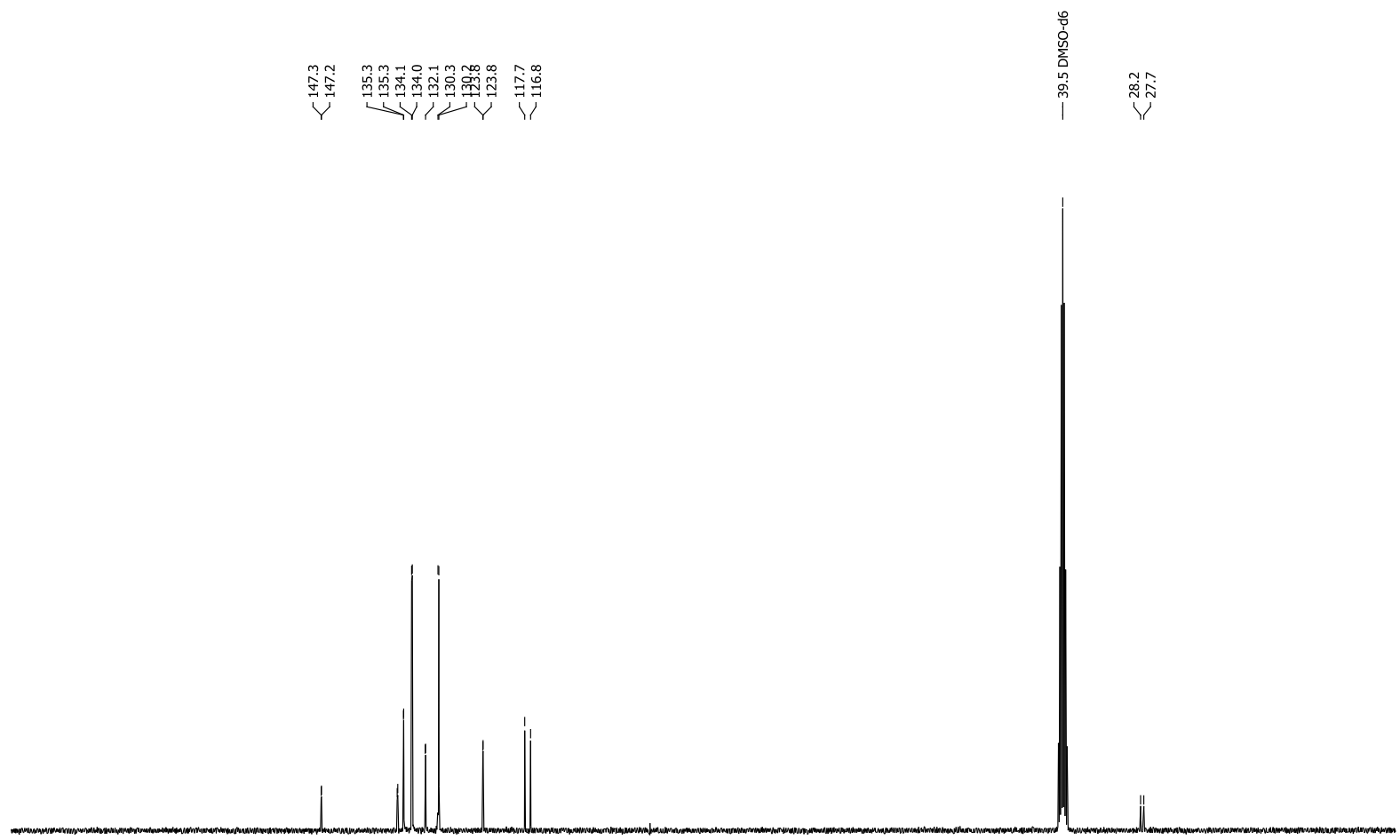
2c, ${ }^{1} \mathrm{H}$ NMR (400 MHz, DMSO)

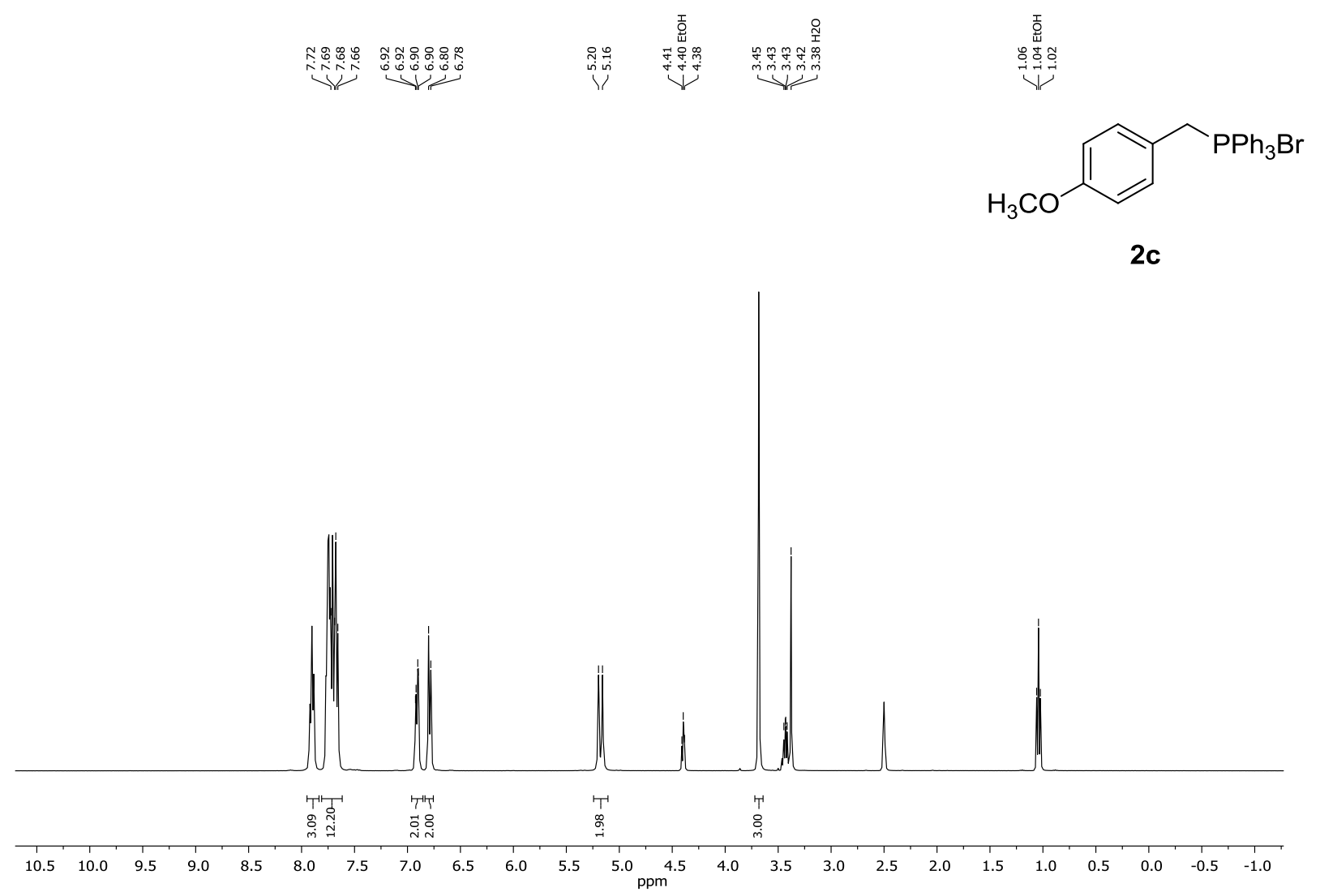

2c, ${ }^{13} \mathrm{C}\left\{{ }^{1} \mathrm{H}\right\}$ NMR (100 MHz, DMSO)
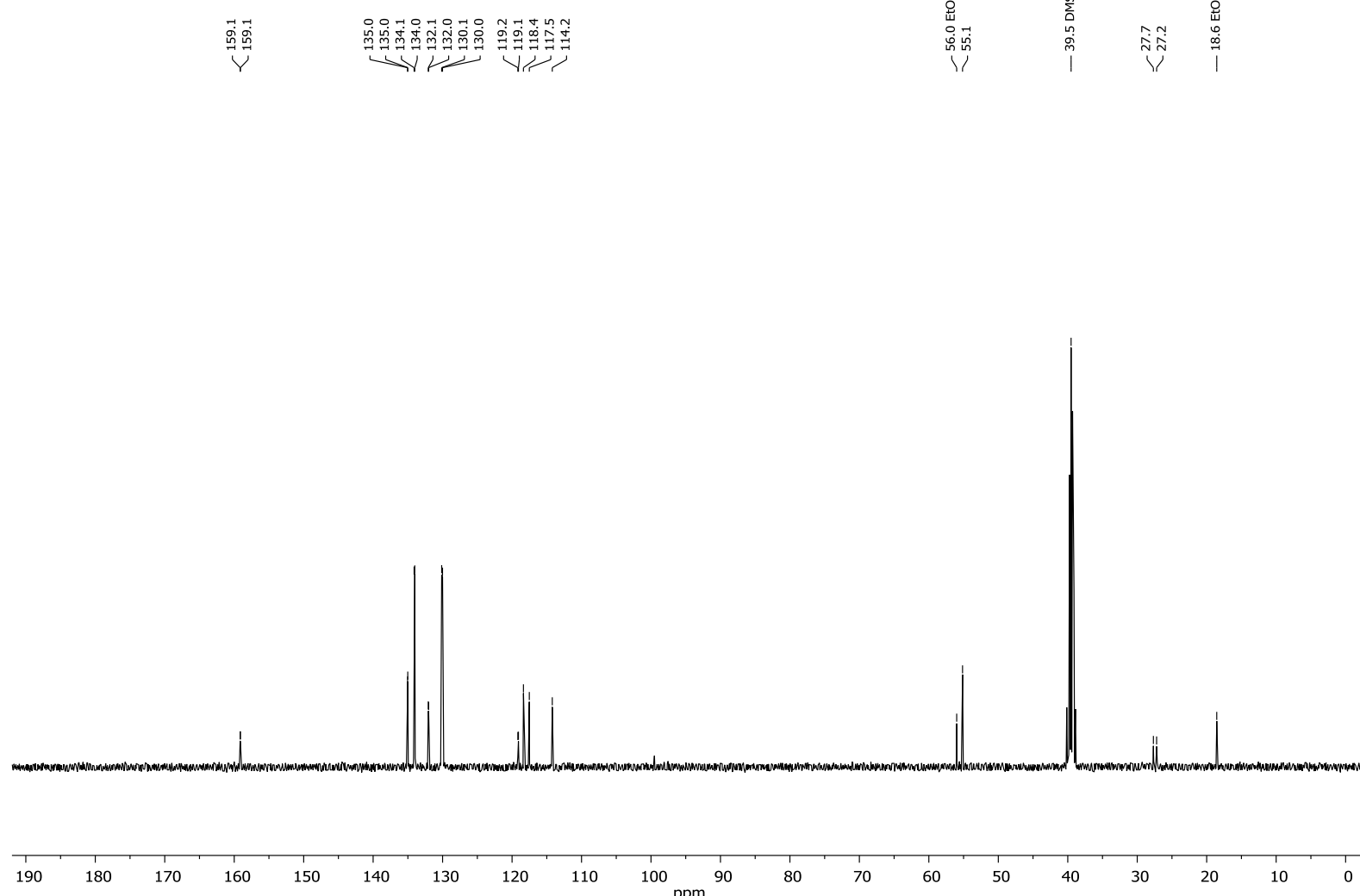
2d, ${ }^{1} \mathrm{H}$ NMR (400 MHz, DMSO)

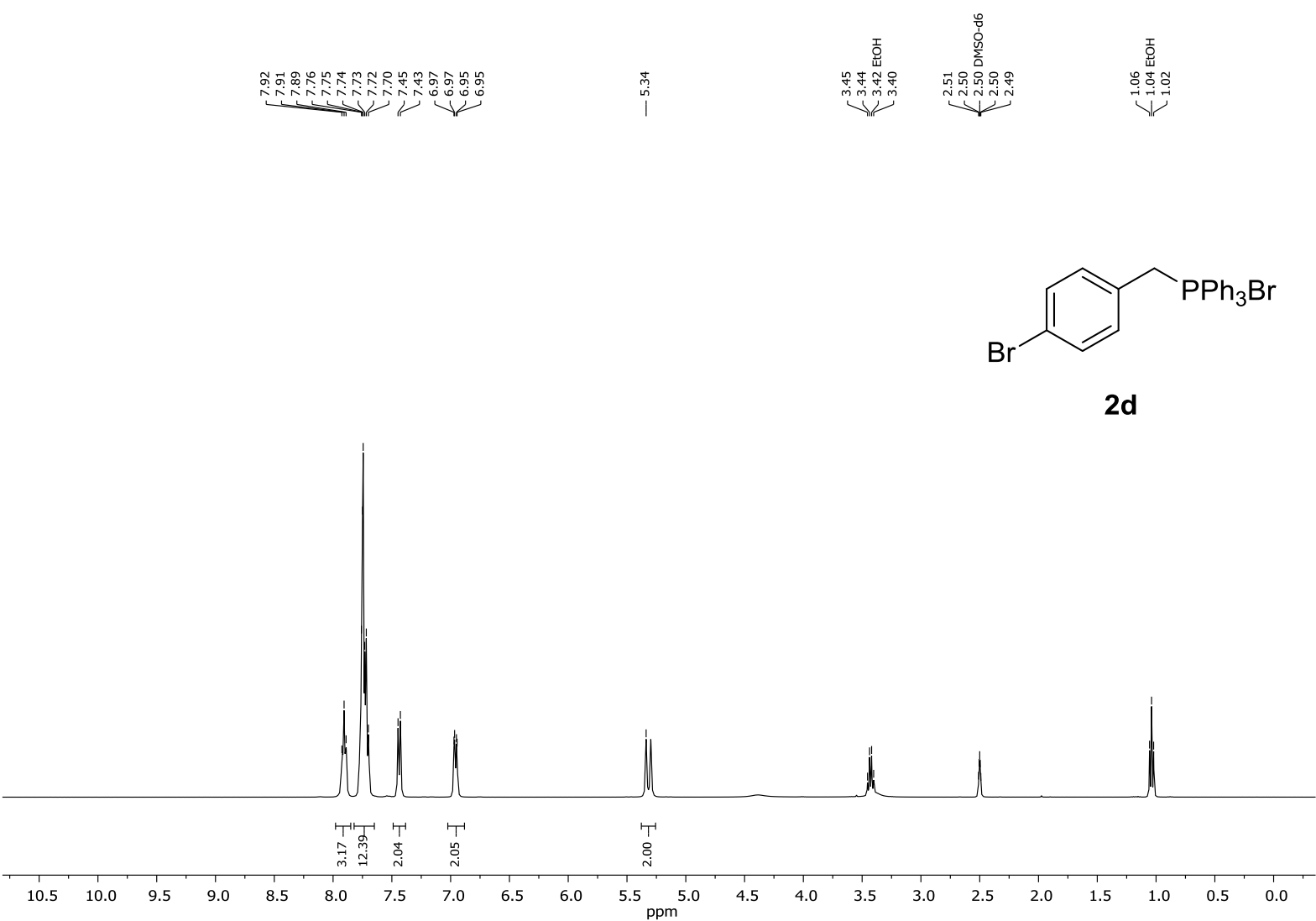

2d, ${ }^{13} \mathrm{C}\left\{{ }^{1} \mathrm{H}\right\}$ NMR (100 MHz, DMSO)

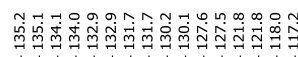
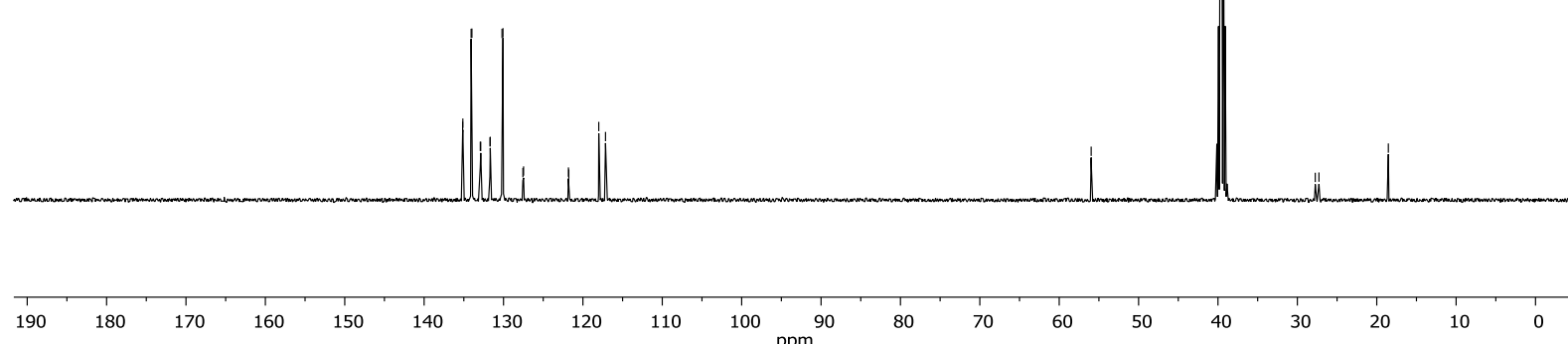
2e, ${ }^{1} \mathrm{H}$ NMR (400 MHz, DMSO)
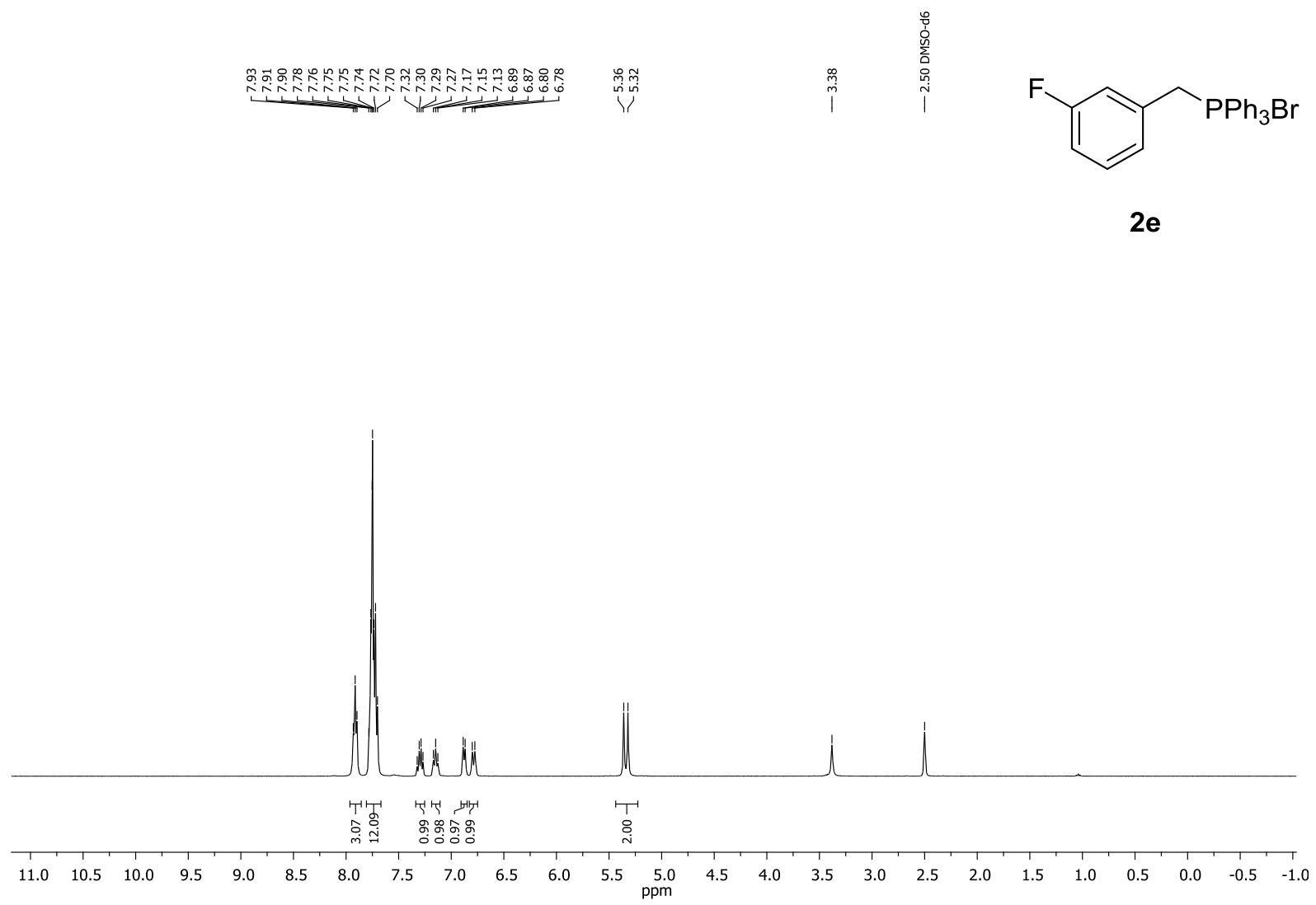

2e, ${ }^{13} \mathrm{C}\left\{{ }^{1} \mathrm{H}\right\}$ NMR (100 MHz, DMSO)

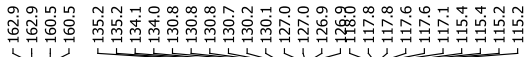

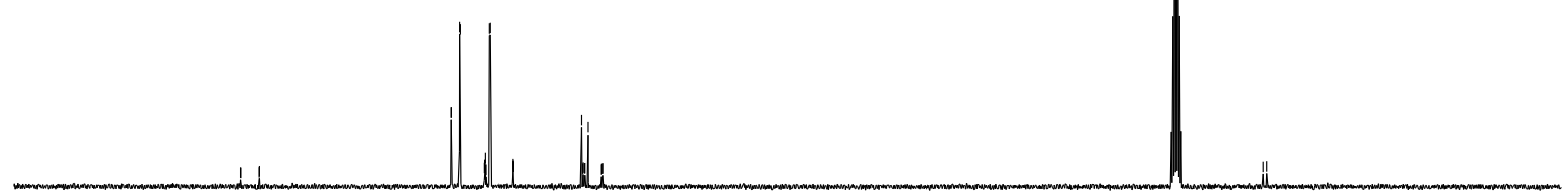

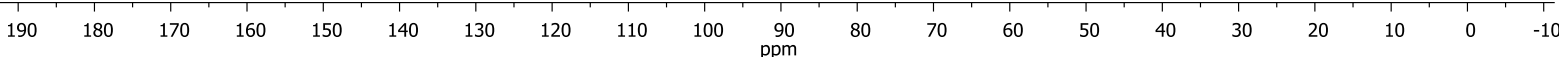


2f, ${ }^{1} \mathrm{H}$ NMR (400 MHz, DMSO)
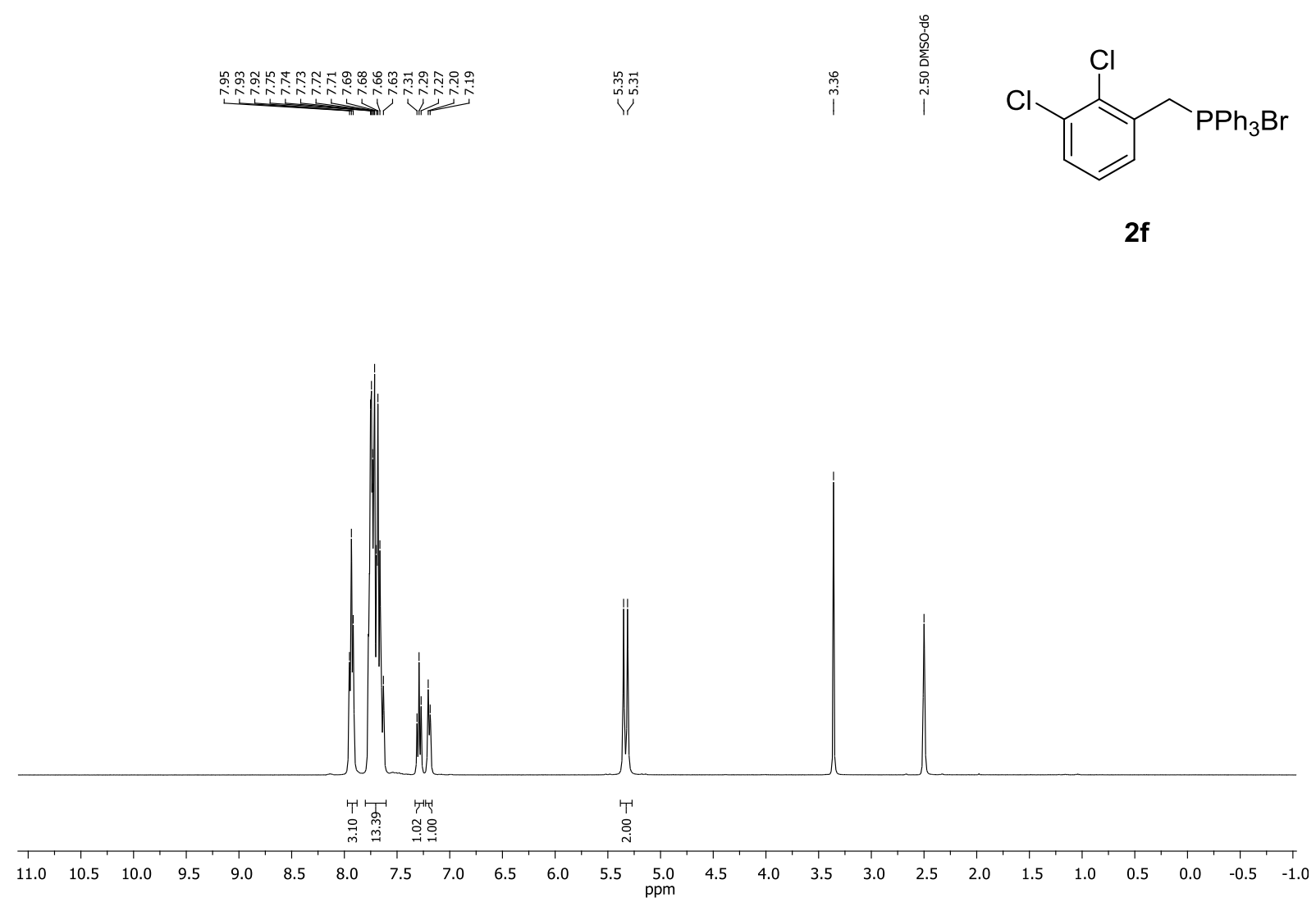

2f, ${ }^{13} \mathrm{C}\left\{{ }^{1} \mathrm{H}\right\}$ NMR (100 MHz, DMSO)

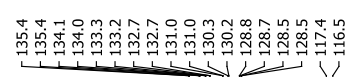

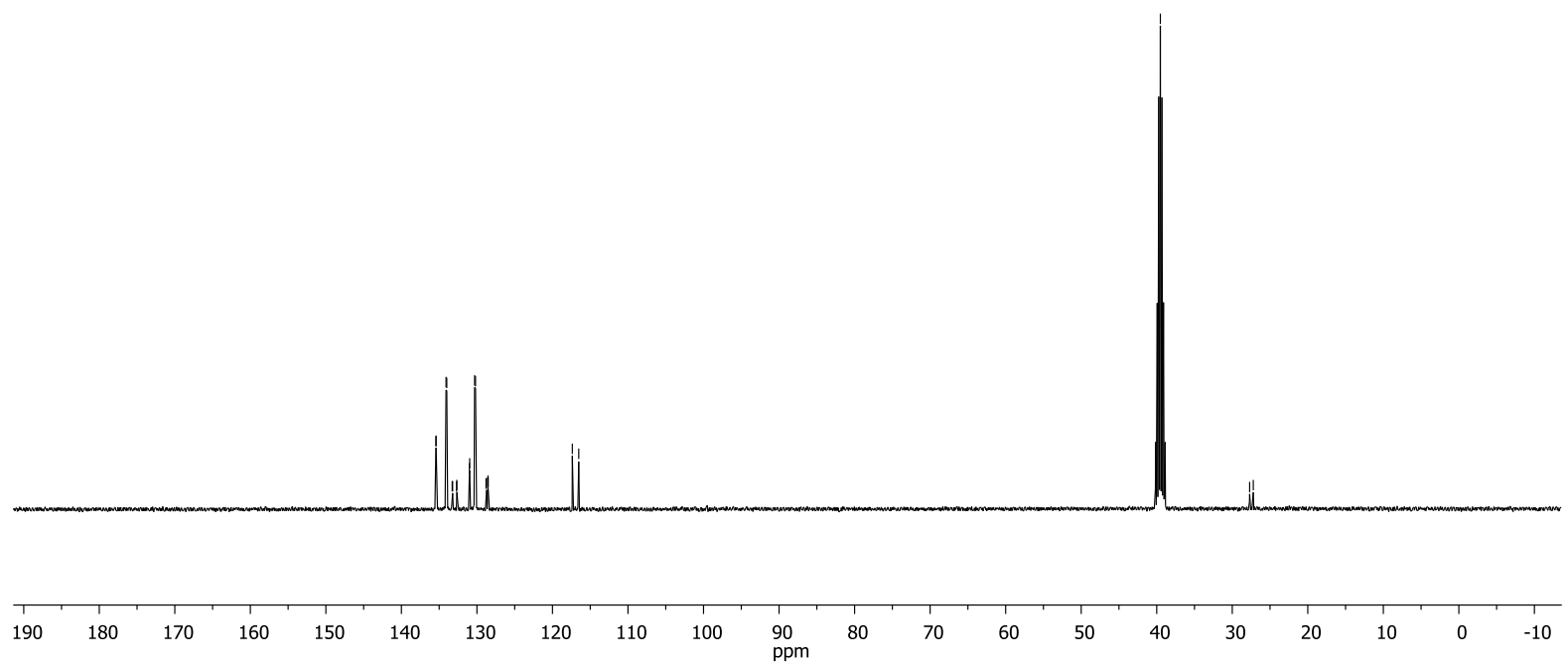


2g, ${ }^{1} \mathrm{H}$ NMR (400 MHz, DMSO)
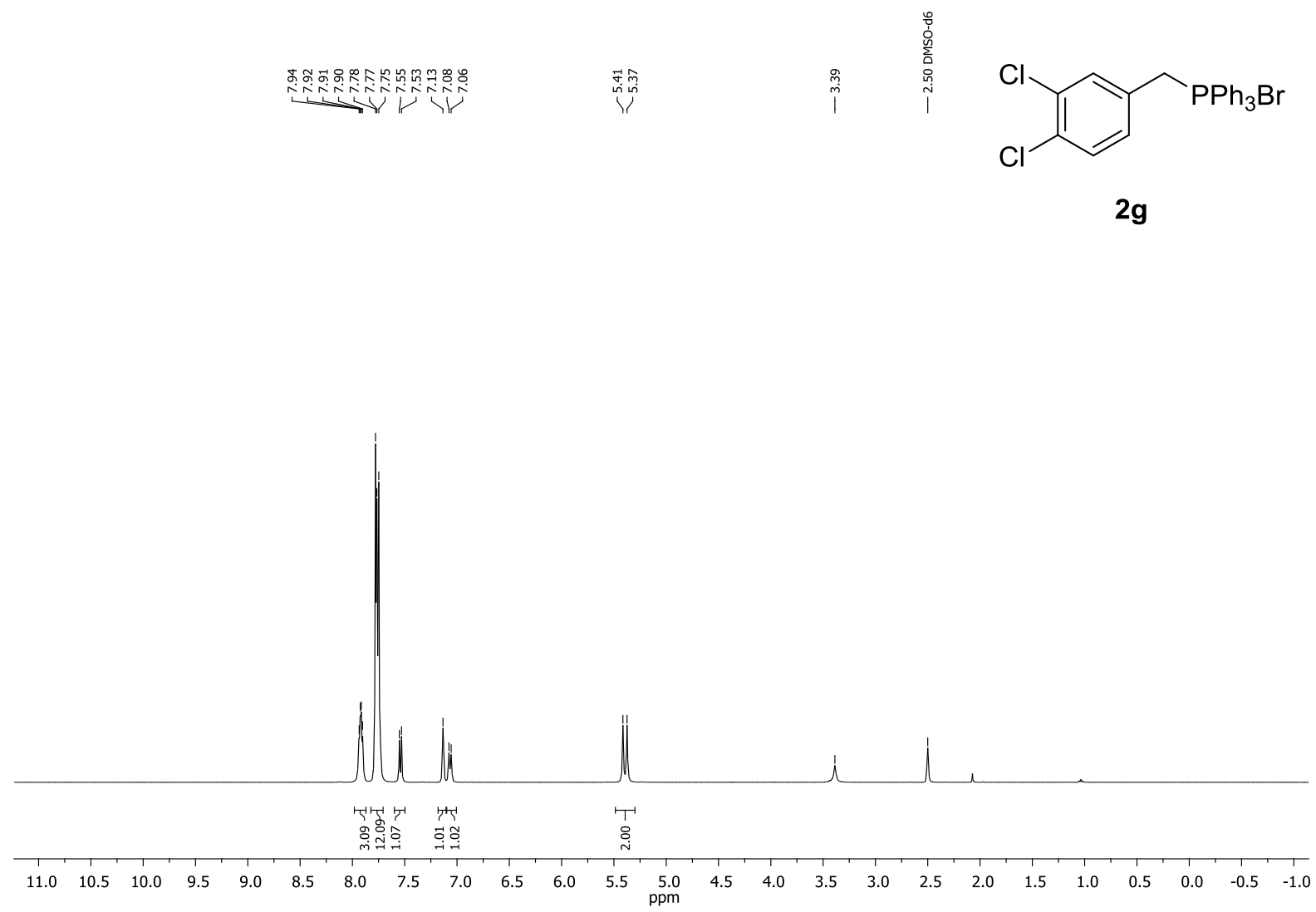

2g, ${ }^{13} \mathrm{C}\left\{{ }^{1} \mathrm{H}\right\}$ NMR (100 MHz, DMSO)

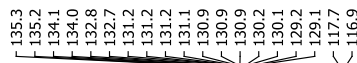
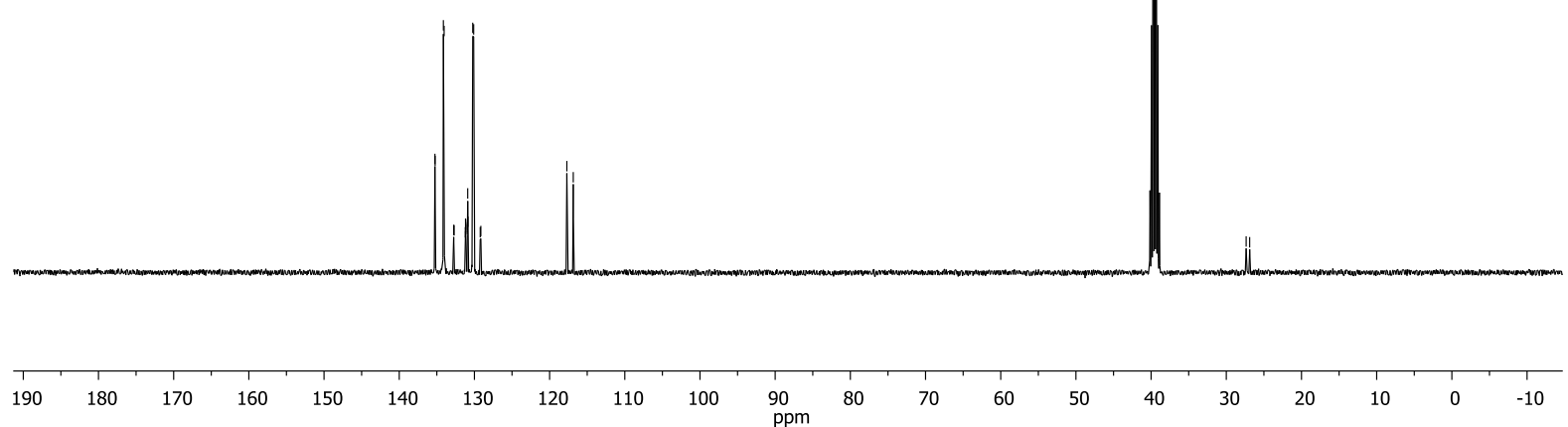
2h, ${ }^{1} \mathrm{H}$ NMR (400 MHz, DMSO)
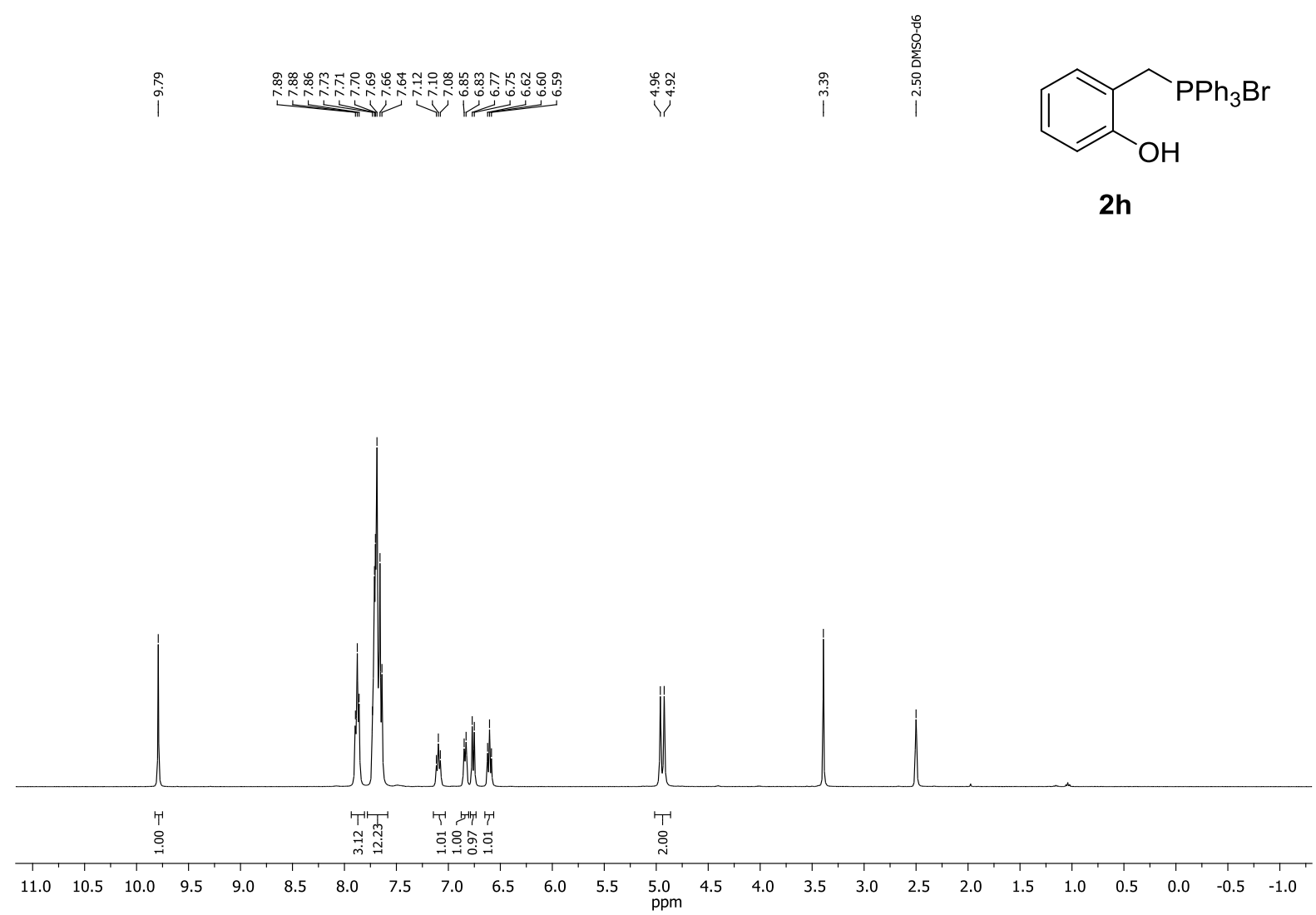

2h, ${ }^{13} \mathrm{C}\left\{{ }^{1} \mathrm{H}\right\}$ NMR $(100 \mathrm{MHz}, \mathrm{DMSO})$
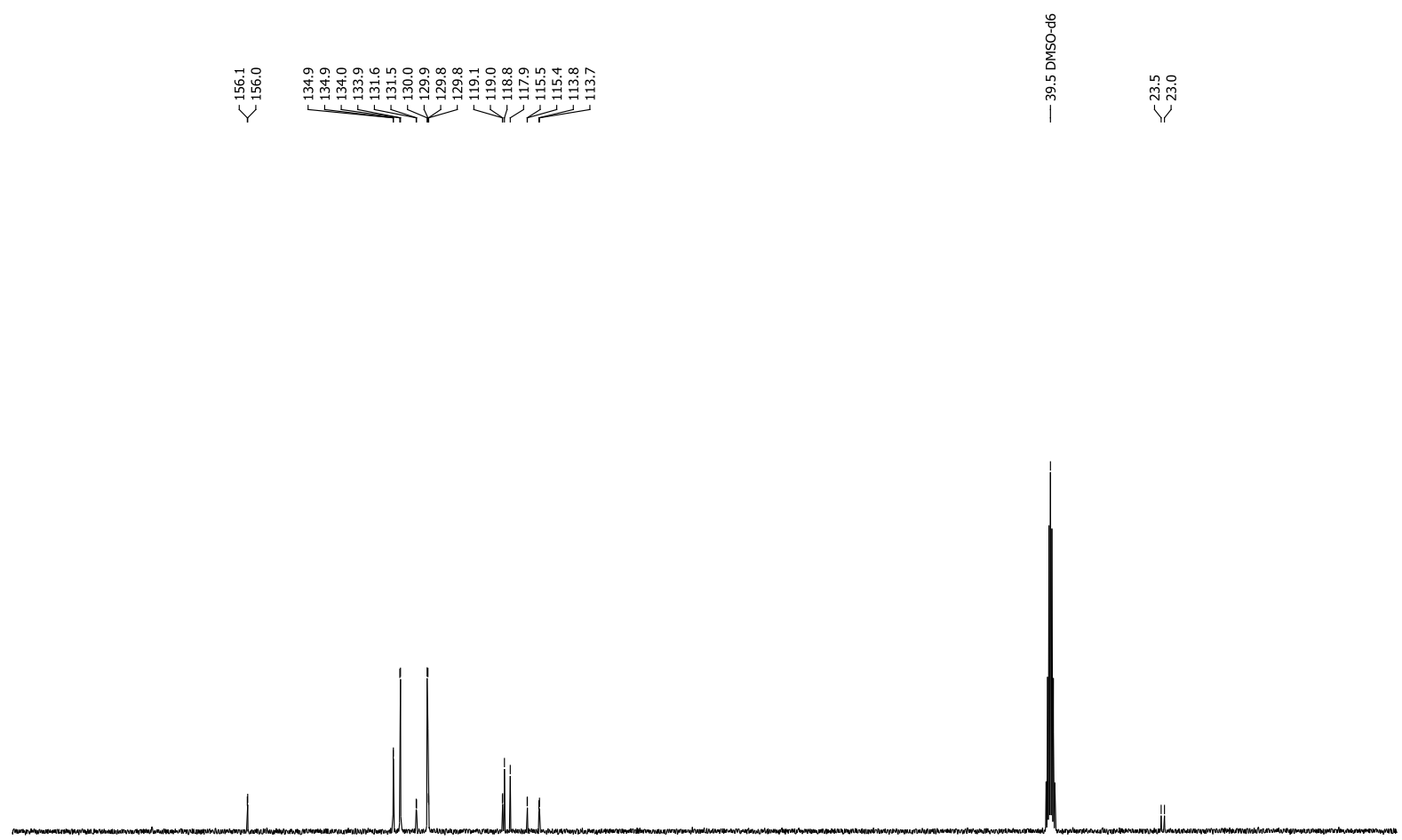

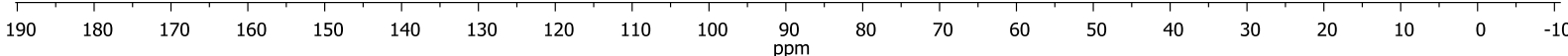


2i, ${ }^{1} \mathrm{H}$ NMR (400 MHz, DMSO)

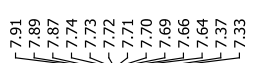

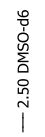

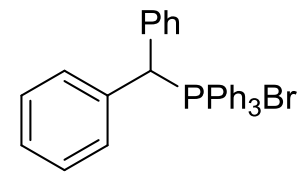

2i

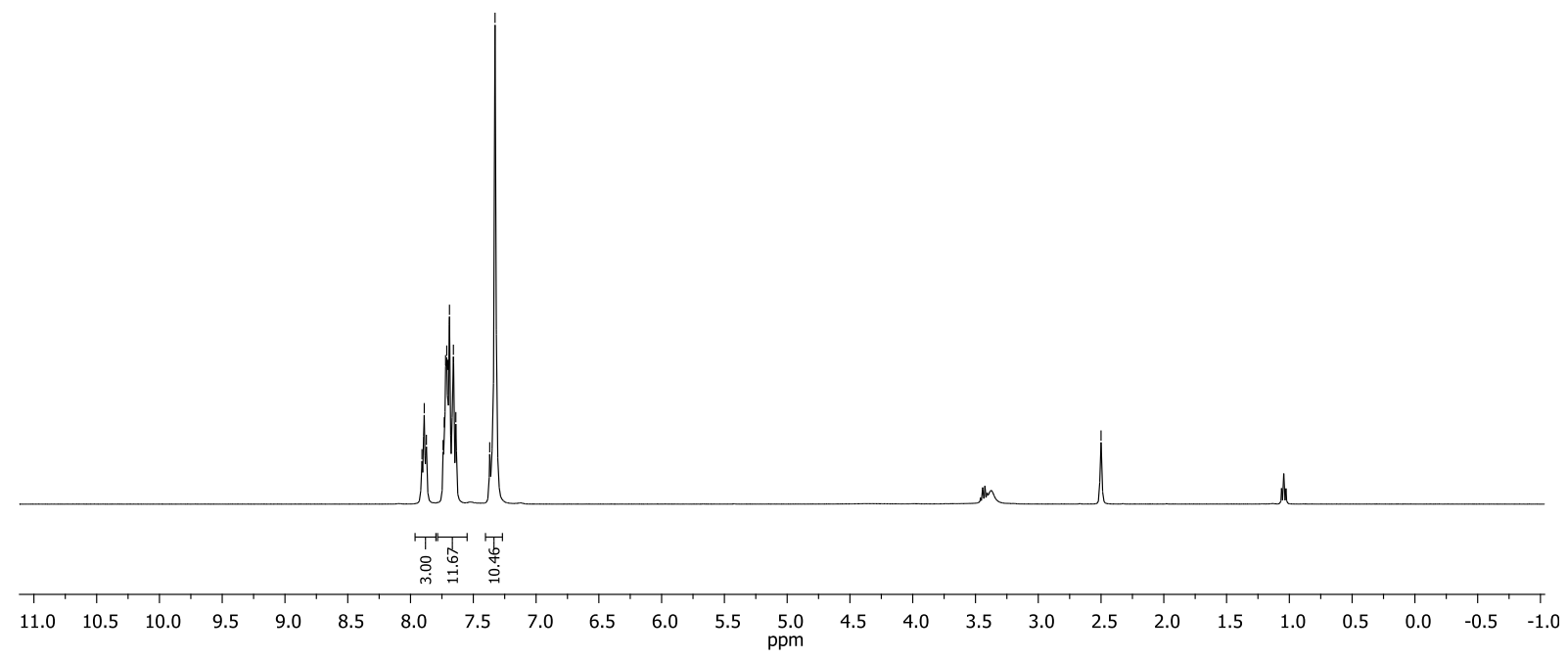

2i, ${ }^{13} \mathrm{C}\left\{{ }^{1} \mathrm{H}\right\}$ NMR (100 MHz, DMSO)

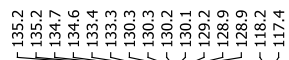
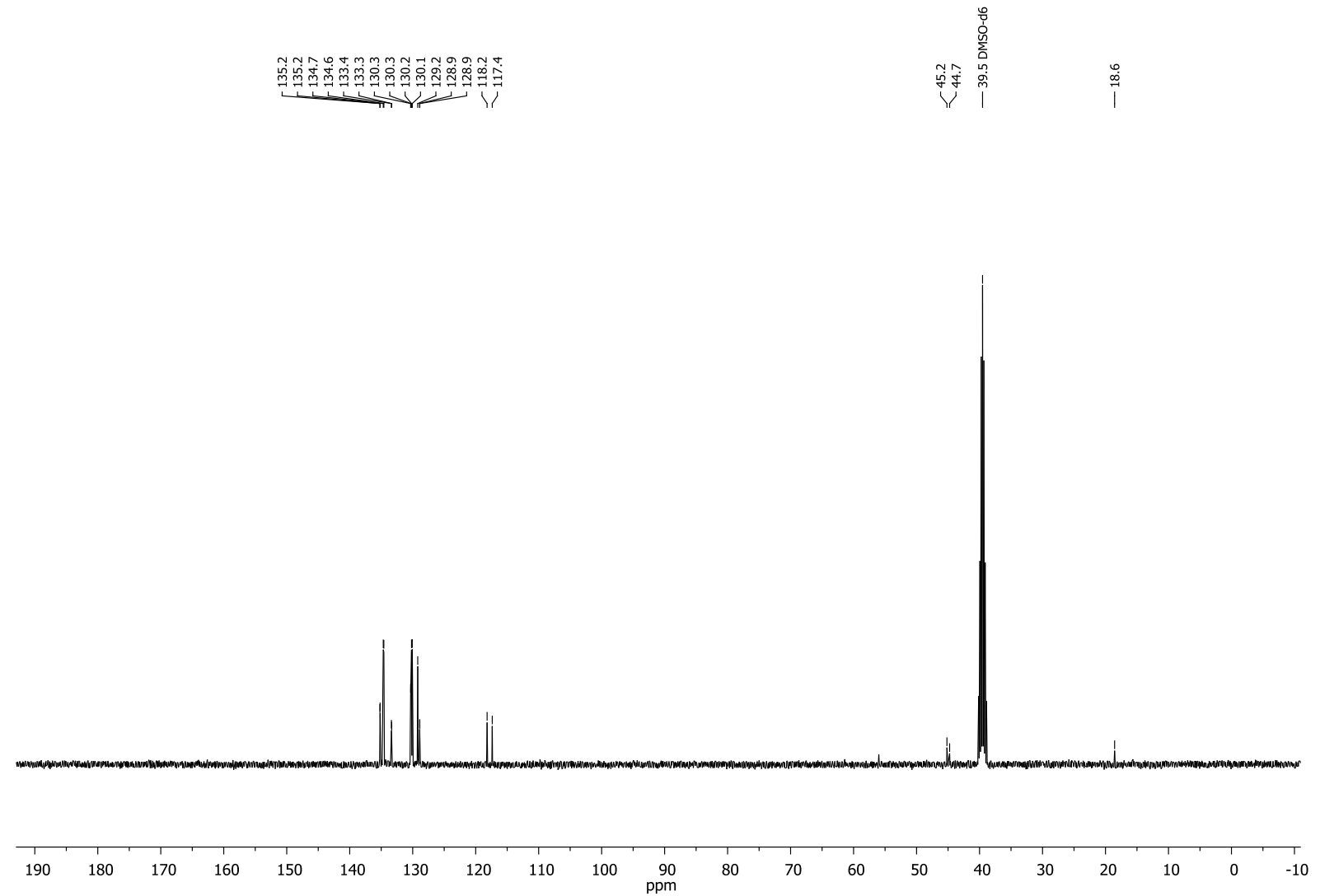
2j, ${ }^{1} \mathrm{H}$ NMR (400 MHz, DMSO)

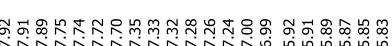

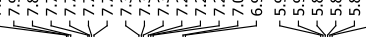

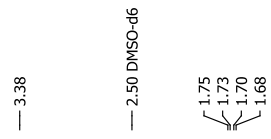

$\overbrace{\mathrm{PPh}_{3} \mathrm{Br}}^{\mathrm{CH}_{3}}$

2j

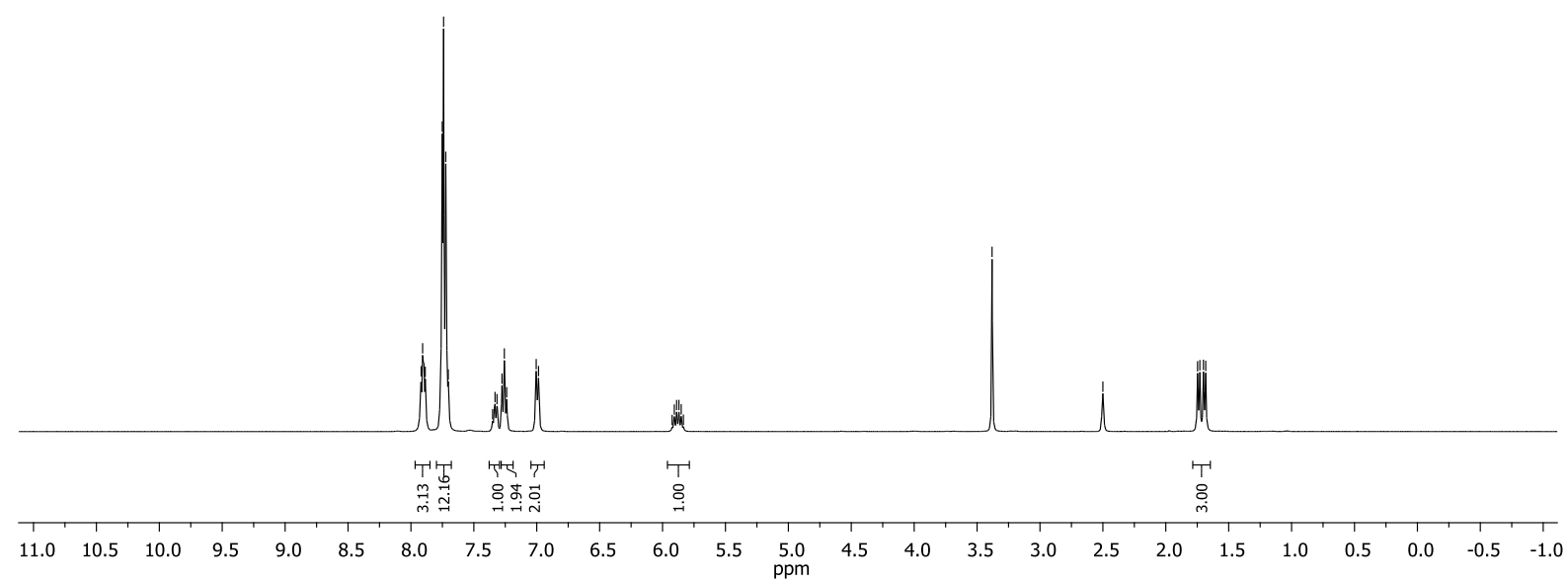

2j, ${ }^{13} \mathrm{C}\left\{{ }^{1} \mathrm{H}\right\}$ NMR (100 MHz, DMSO)

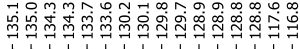
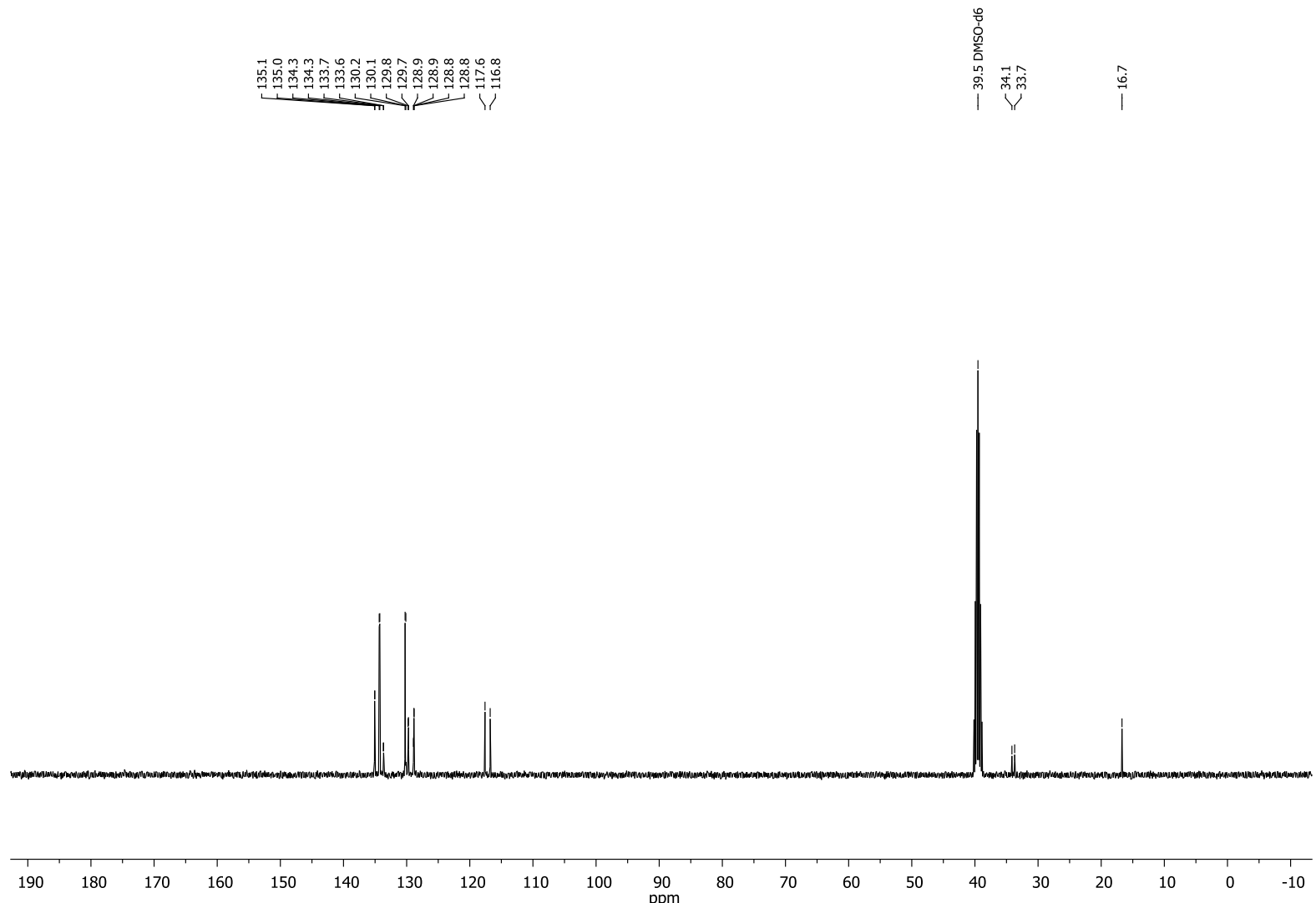
2k, ${ }^{1} \mathrm{H}$ NMR (400 MHz, DMSO)
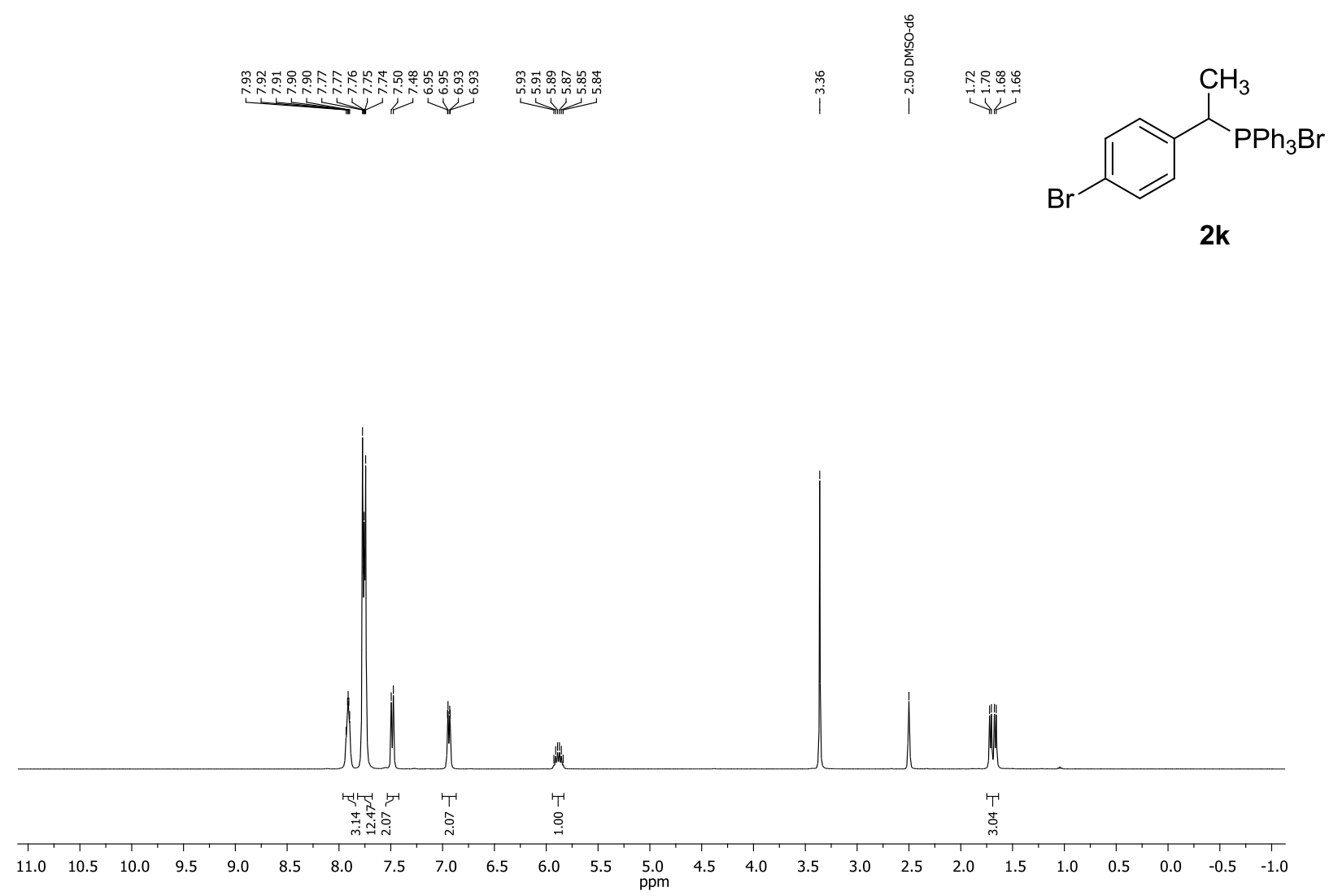

2k, ${ }^{13} \mathrm{C}\left\{{ }^{1} \mathrm{H}\right\}$ NMR (100 MHz, DMSO)

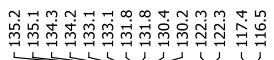
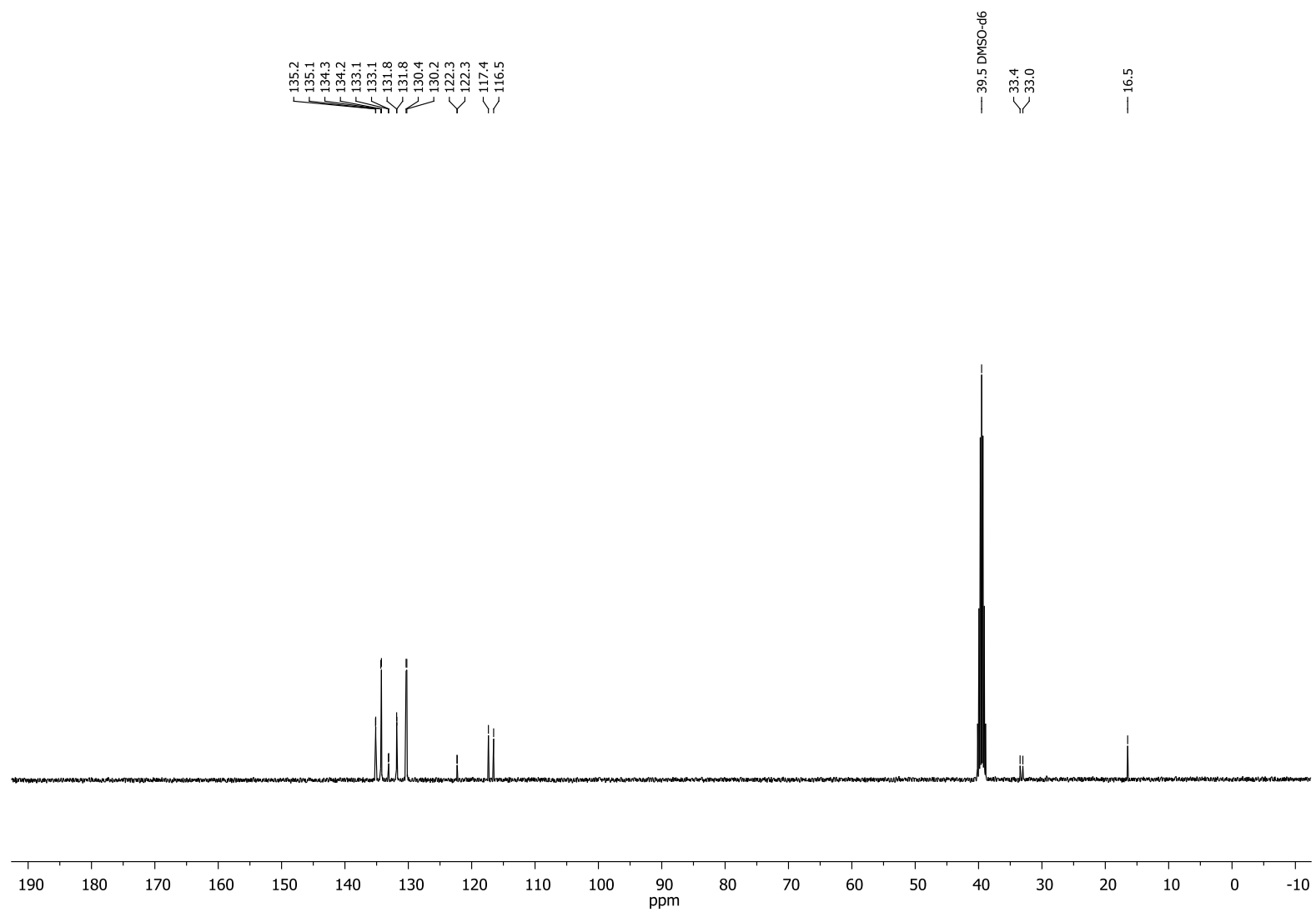
2l, ${ }^{1} \mathrm{H}$ NMR (400 MHz, DMSO)
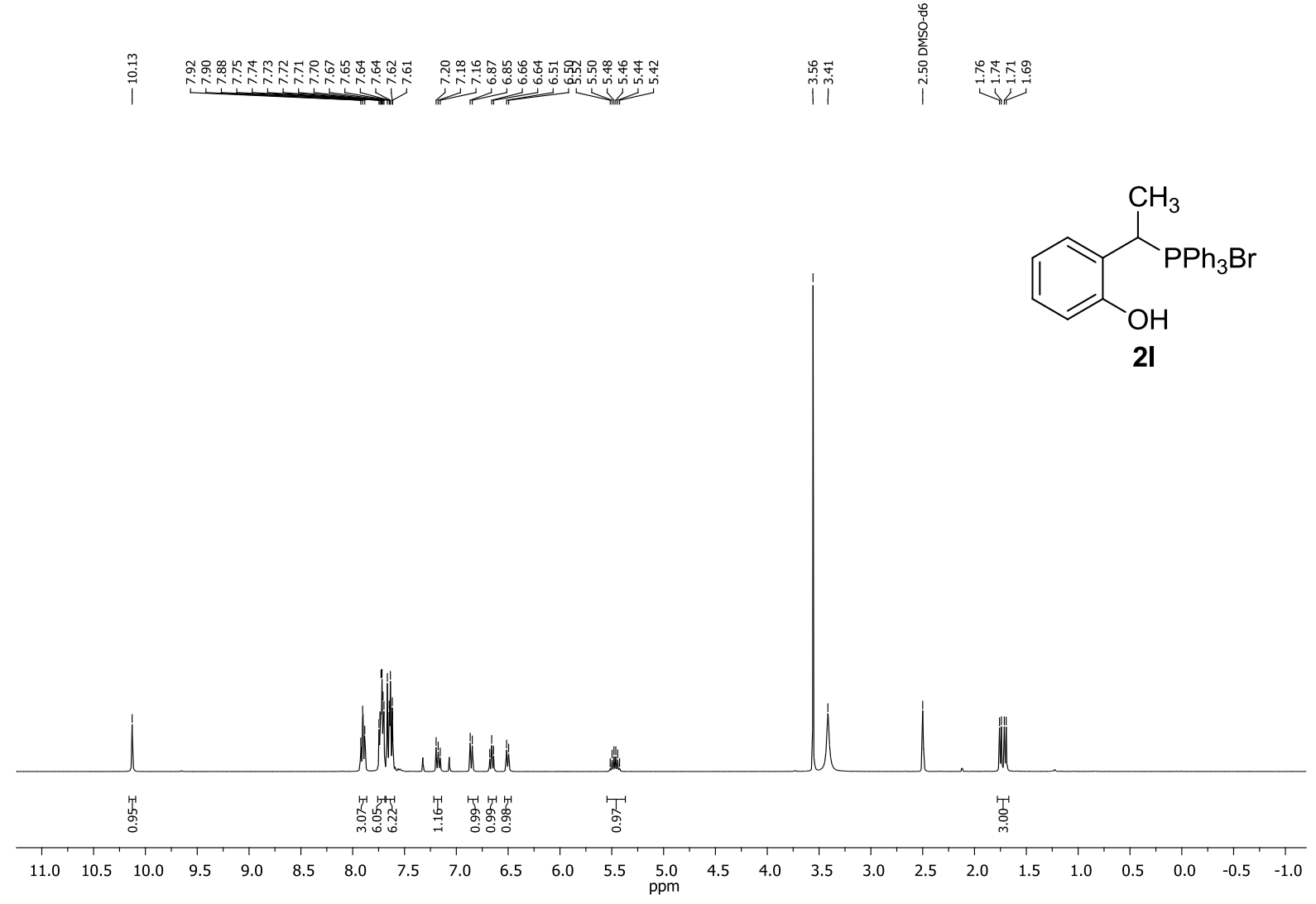

2l, ${ }^{13} \mathrm{C}\left\{{ }^{1} \mathrm{H}\right\}$ NMR (100 MHz, DMSO)
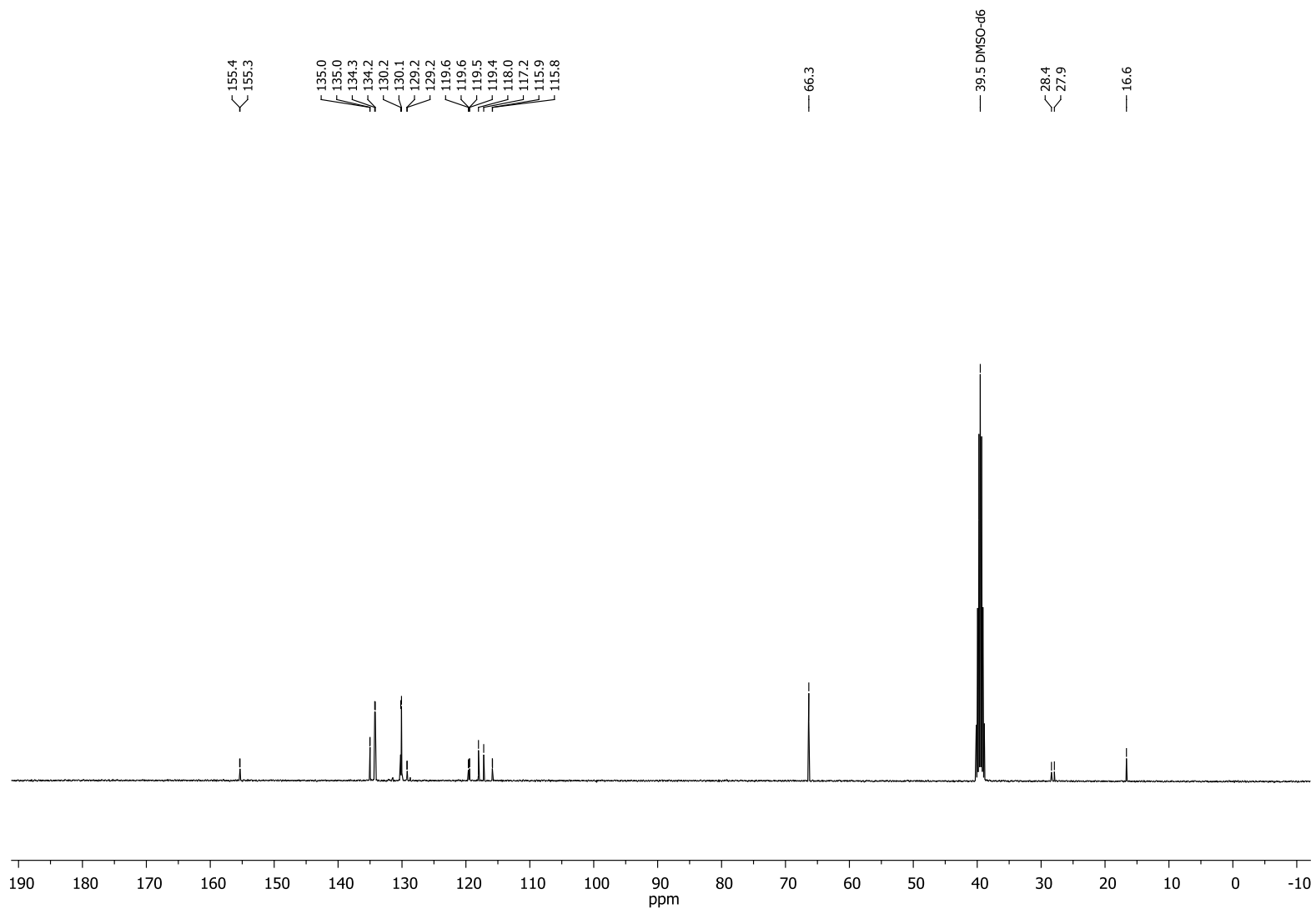
2m, ${ }^{1} \mathrm{H}$ NMR (400 MHz, DMSO)
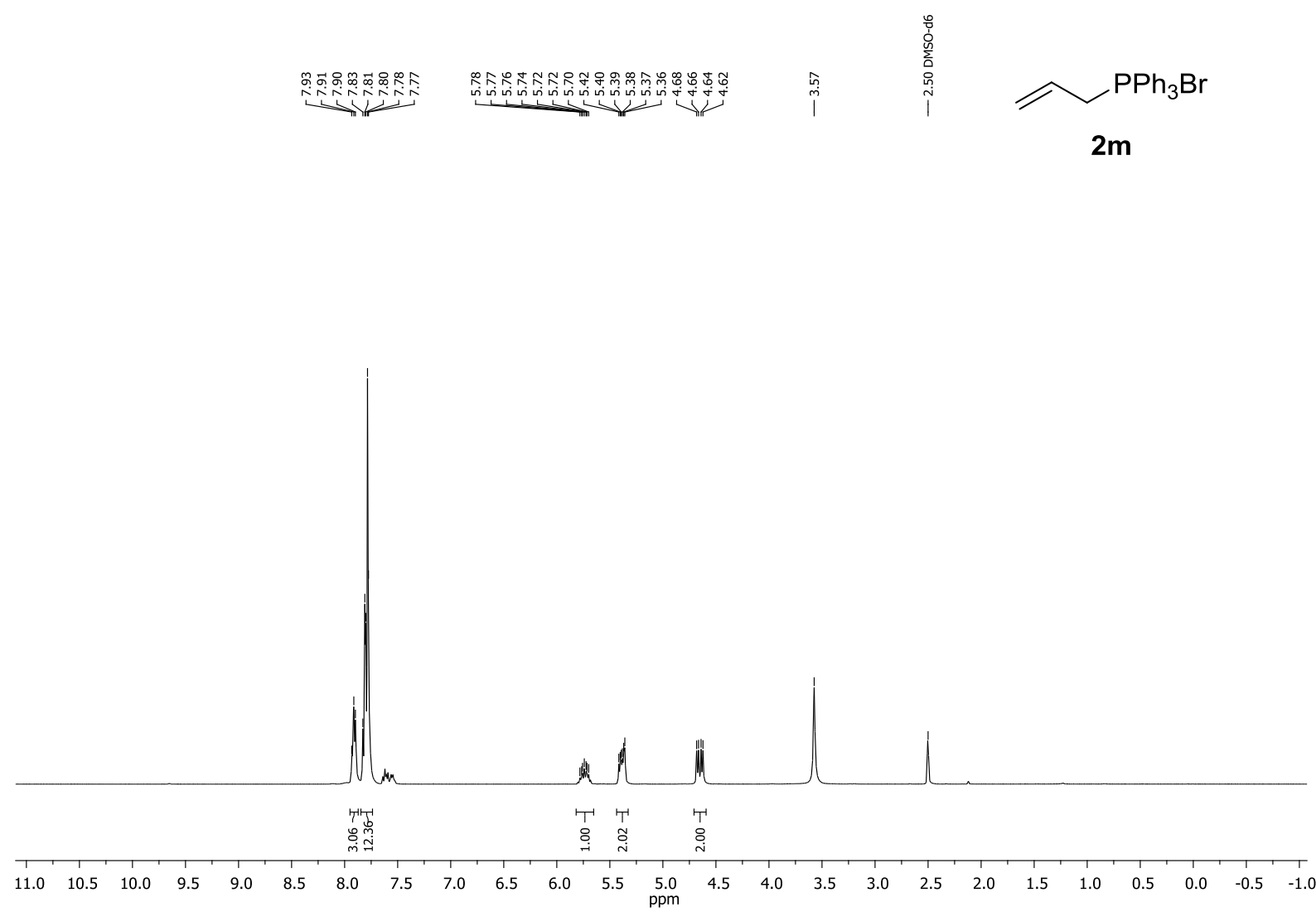

2m, ${ }^{13} \mathrm{C}\left\{{ }^{1} \mathrm{H}\right\}$ NMR (100 MHz, DMSO)

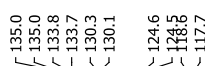
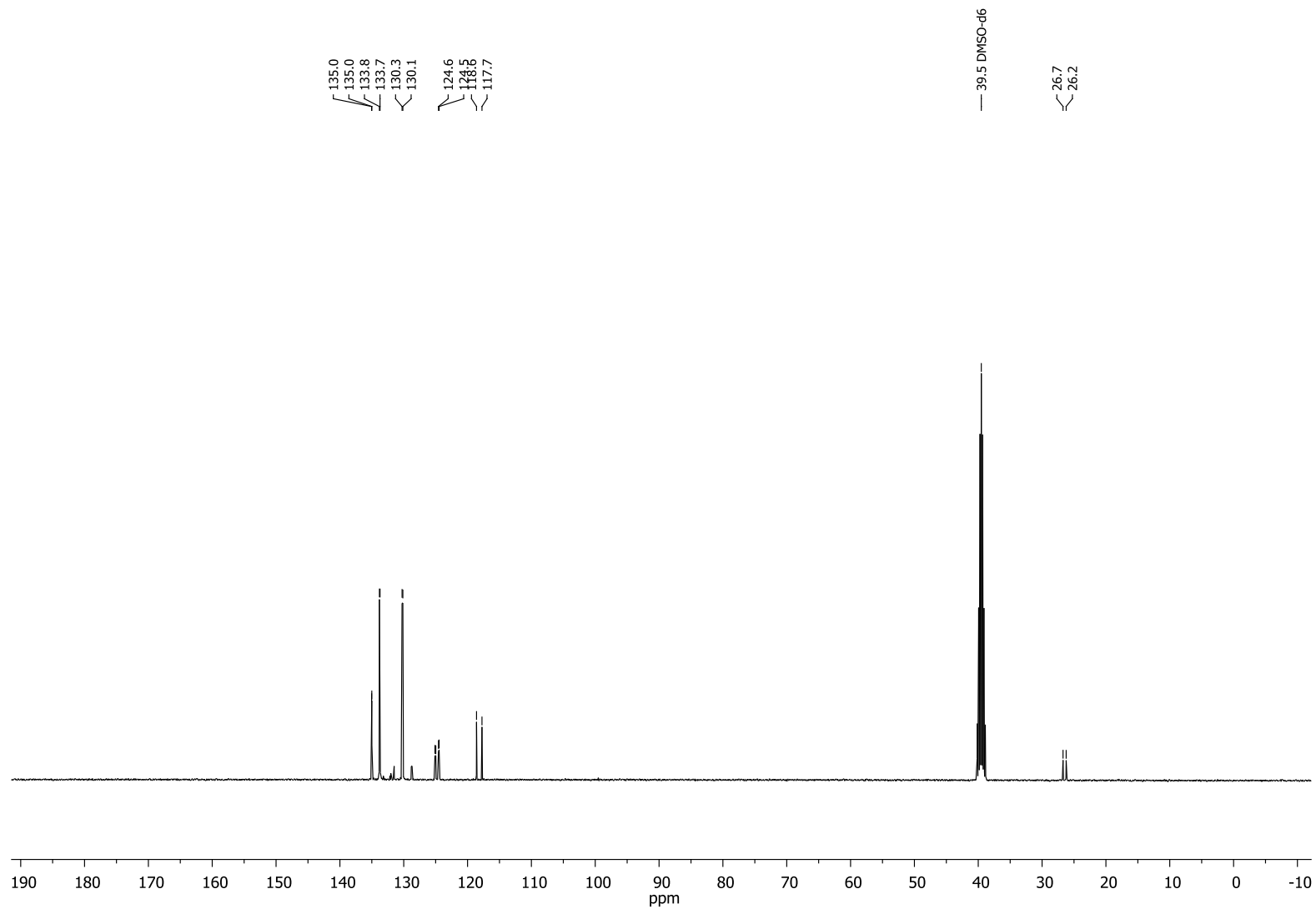
4a, ${ }^{1} \mathrm{H}$ NMR (400 MHz, DMSO)

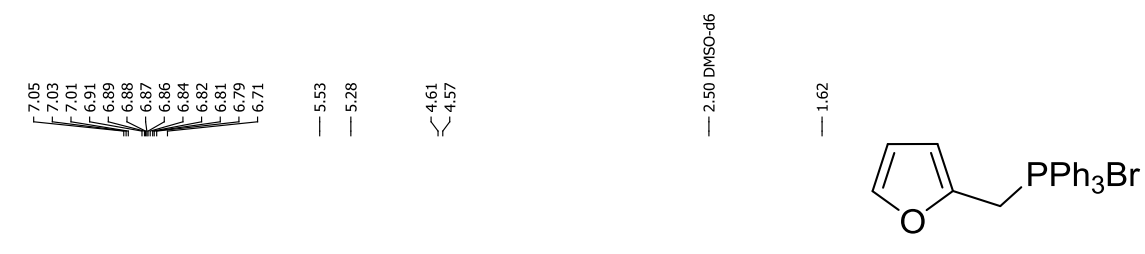

$4 a$

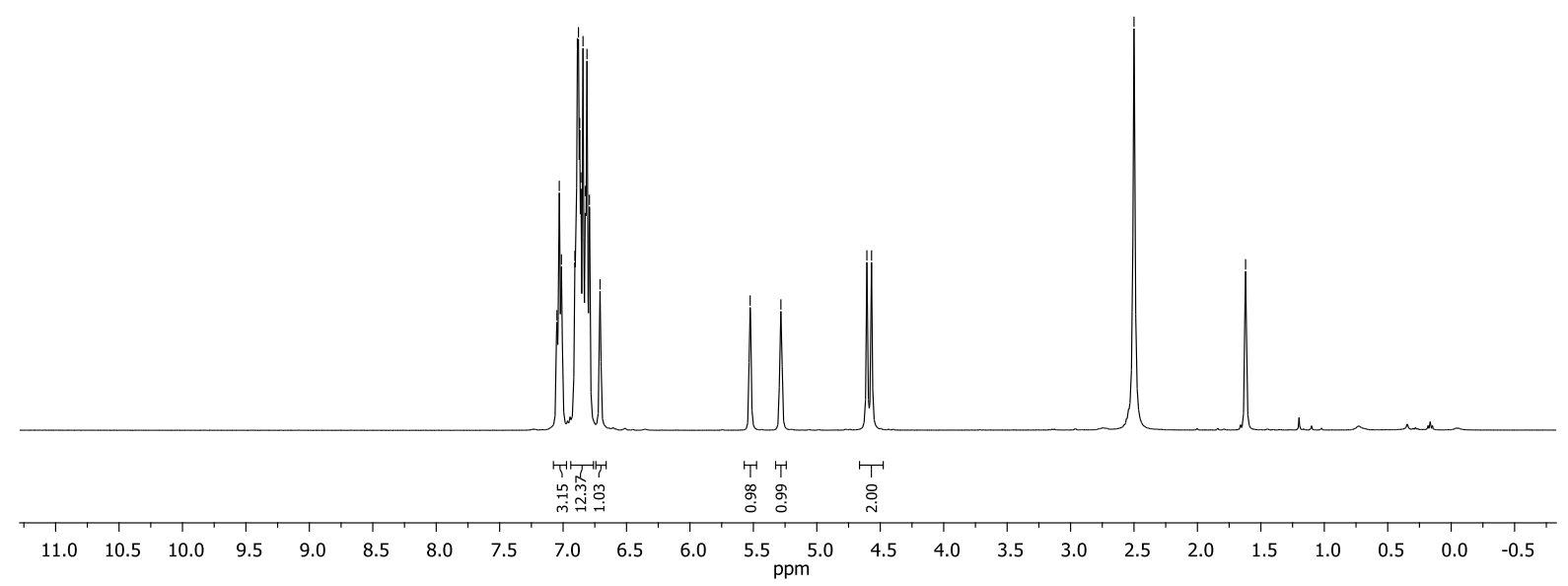

4a, ${ }^{13} \mathrm{C}\left\{{ }^{1} \mathrm{H}\right\}$ NMR (100 MHz, DMSO)

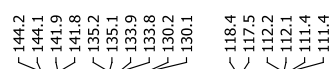

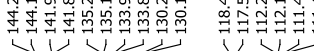
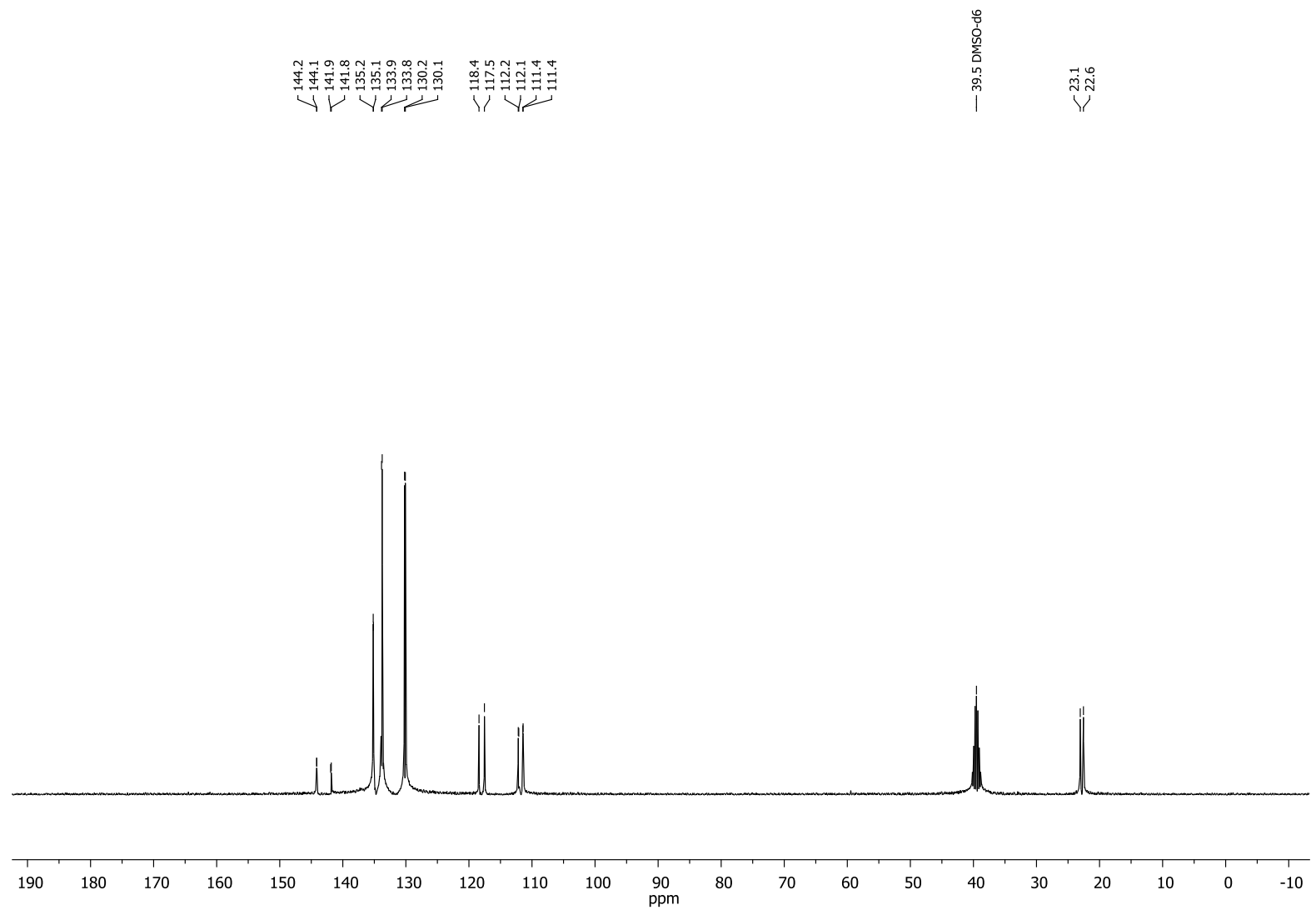
4b, ${ }^{1} \mathrm{H}$ NMR (400 MHz, DMSO)

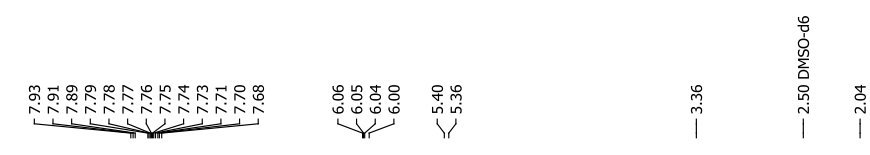

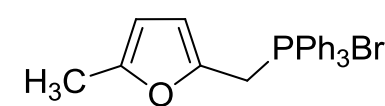

4b

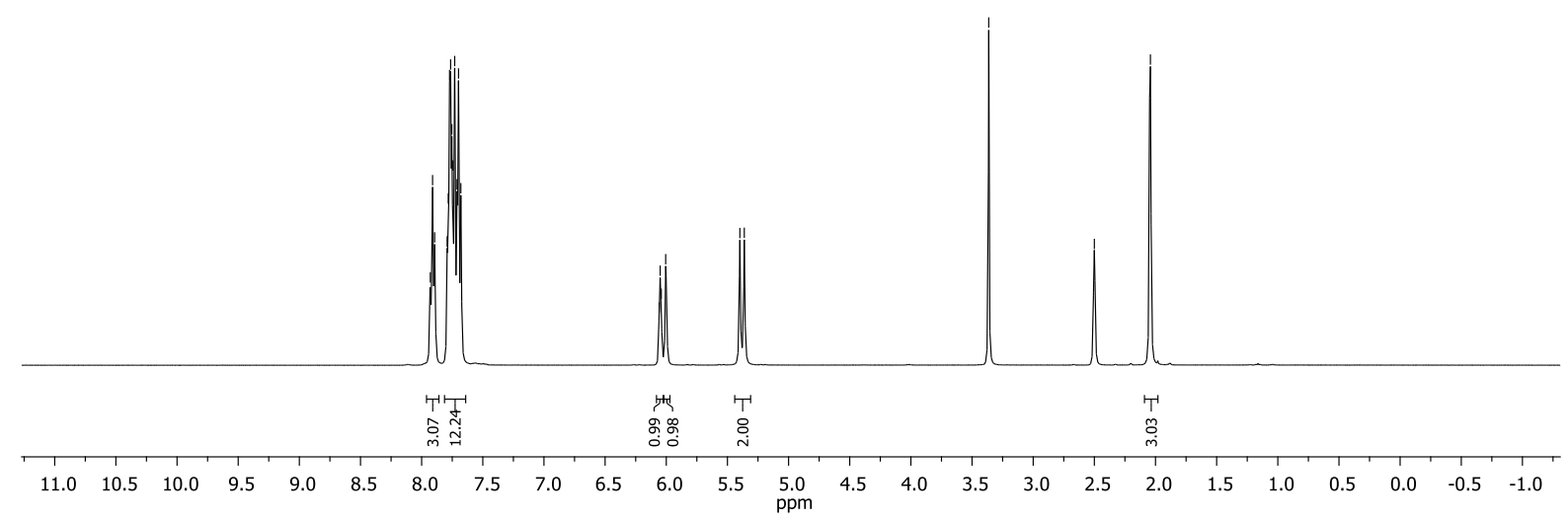

4b, ${ }^{13} \mathrm{C}\left\{{ }^{1} \mathrm{H}\right\}$ NMR (100 MHz, DMSO)
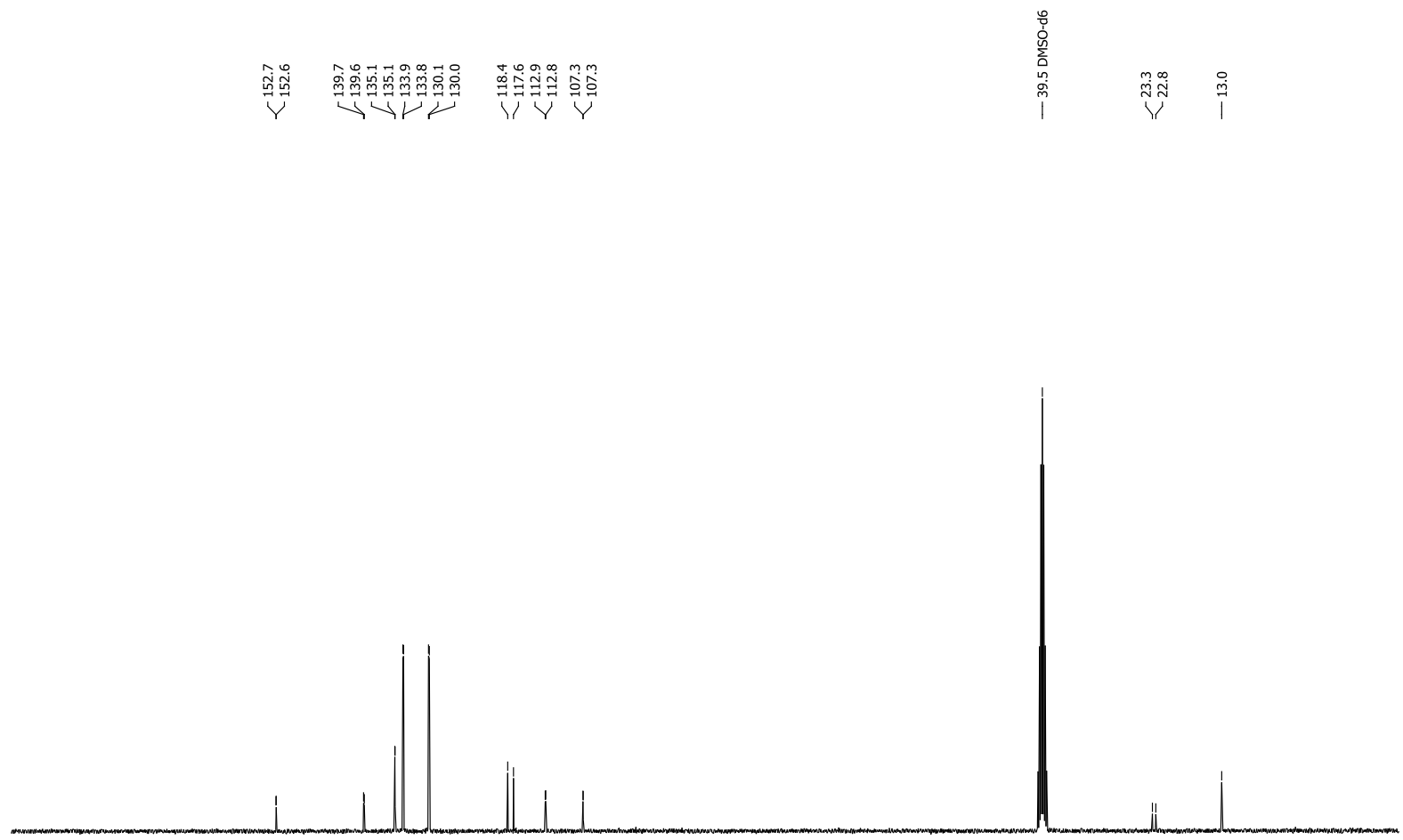

190

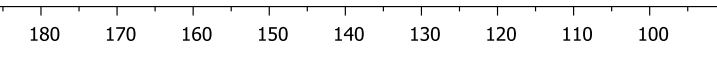

90
$\mathrm{ppm}$ 
4c, ${ }^{1} \mathrm{H}$ NMR (400 MHz, DMSO)

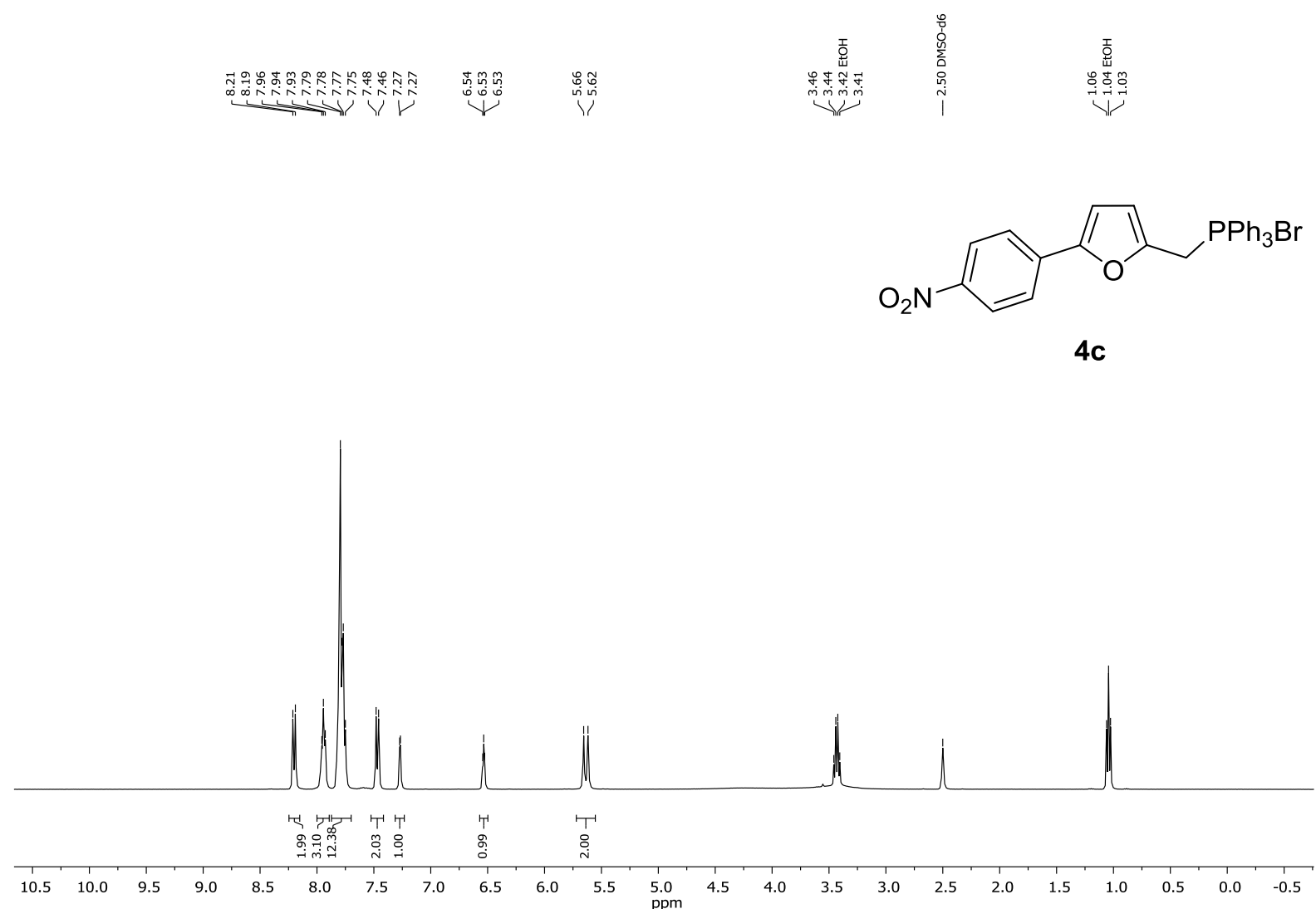

4c, ${ }^{13} \mathrm{C}\left\{{ }^{1} \mathrm{H}\right\}$ NMR (100 MHz, DMSO)

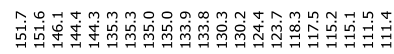
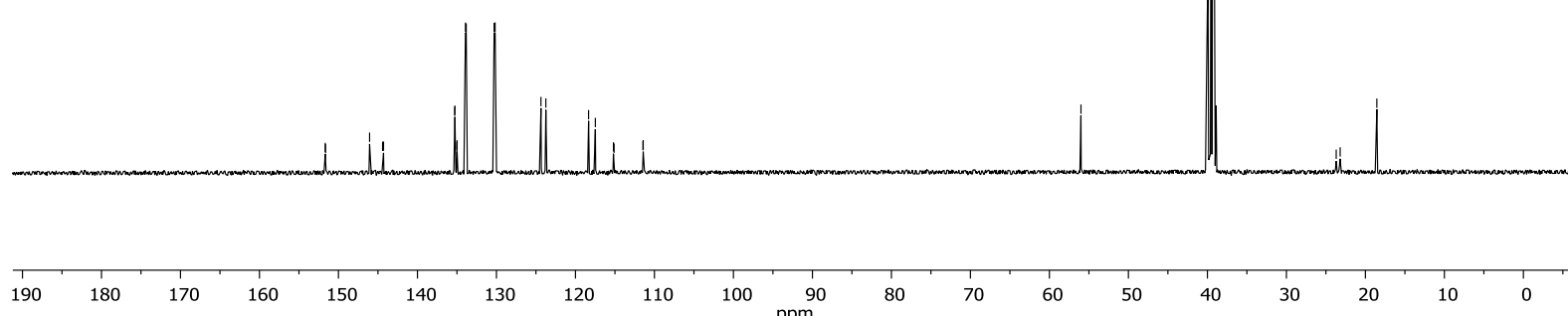
4d, ${ }^{1} \mathrm{H}$ NMR (400 MHz, DMSO)
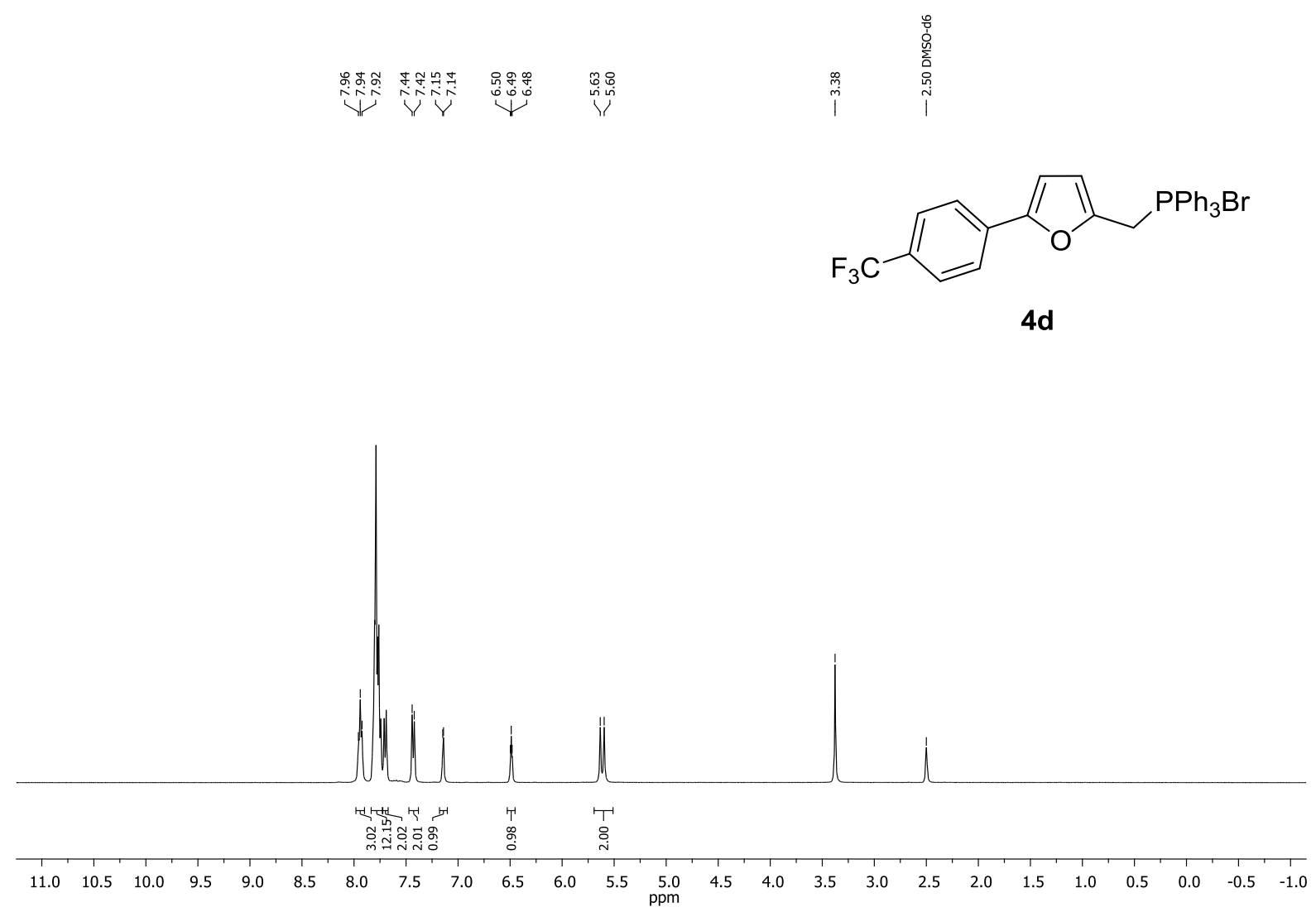

4d, ${ }^{13} \mathrm{C}\left\{{ }^{1} \mathrm{H}\right\}$ NMR (100 MHz, DMSO)
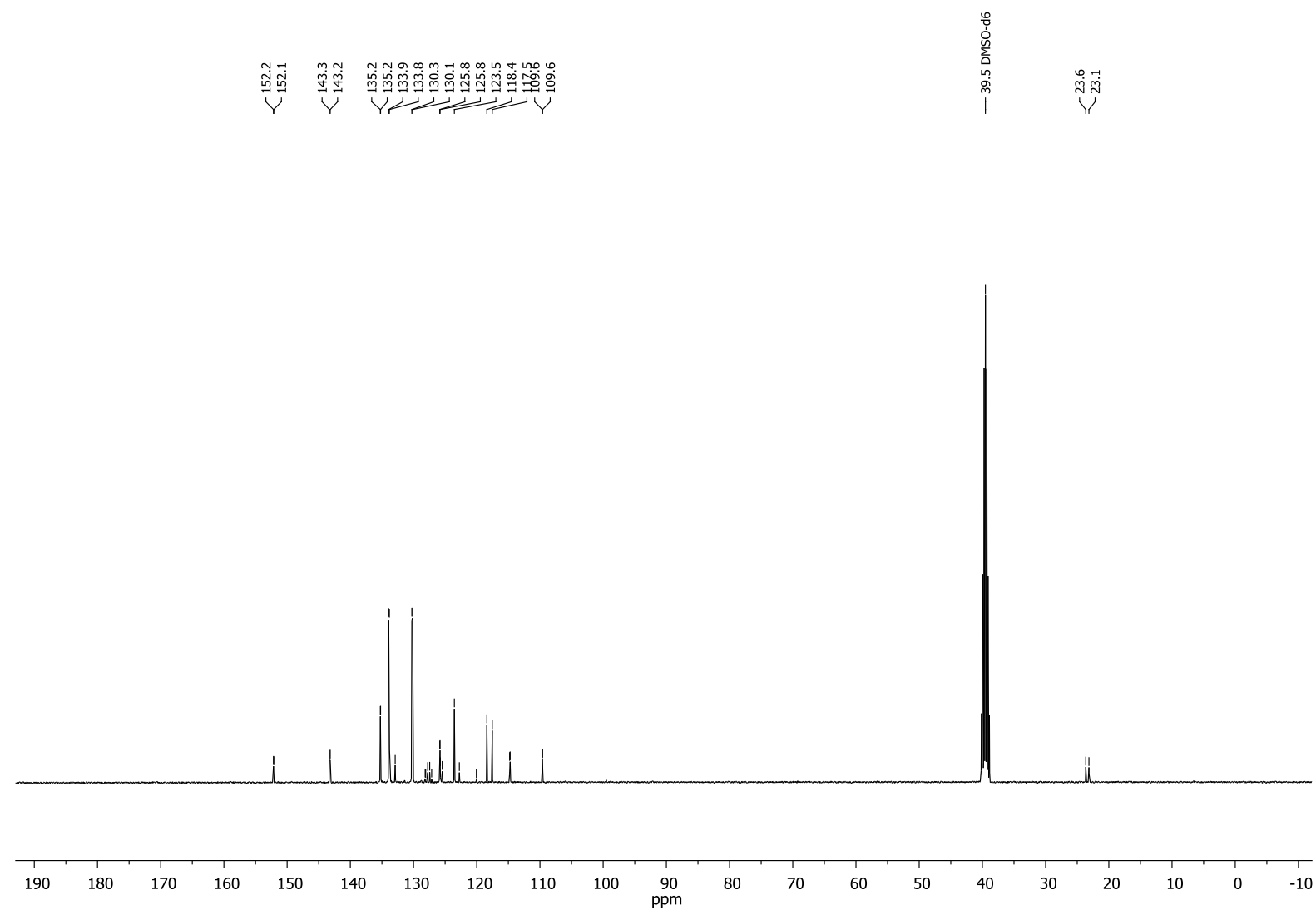
4e, ${ }^{1} \mathrm{H}$ NMR (400 MHz, DMSO)

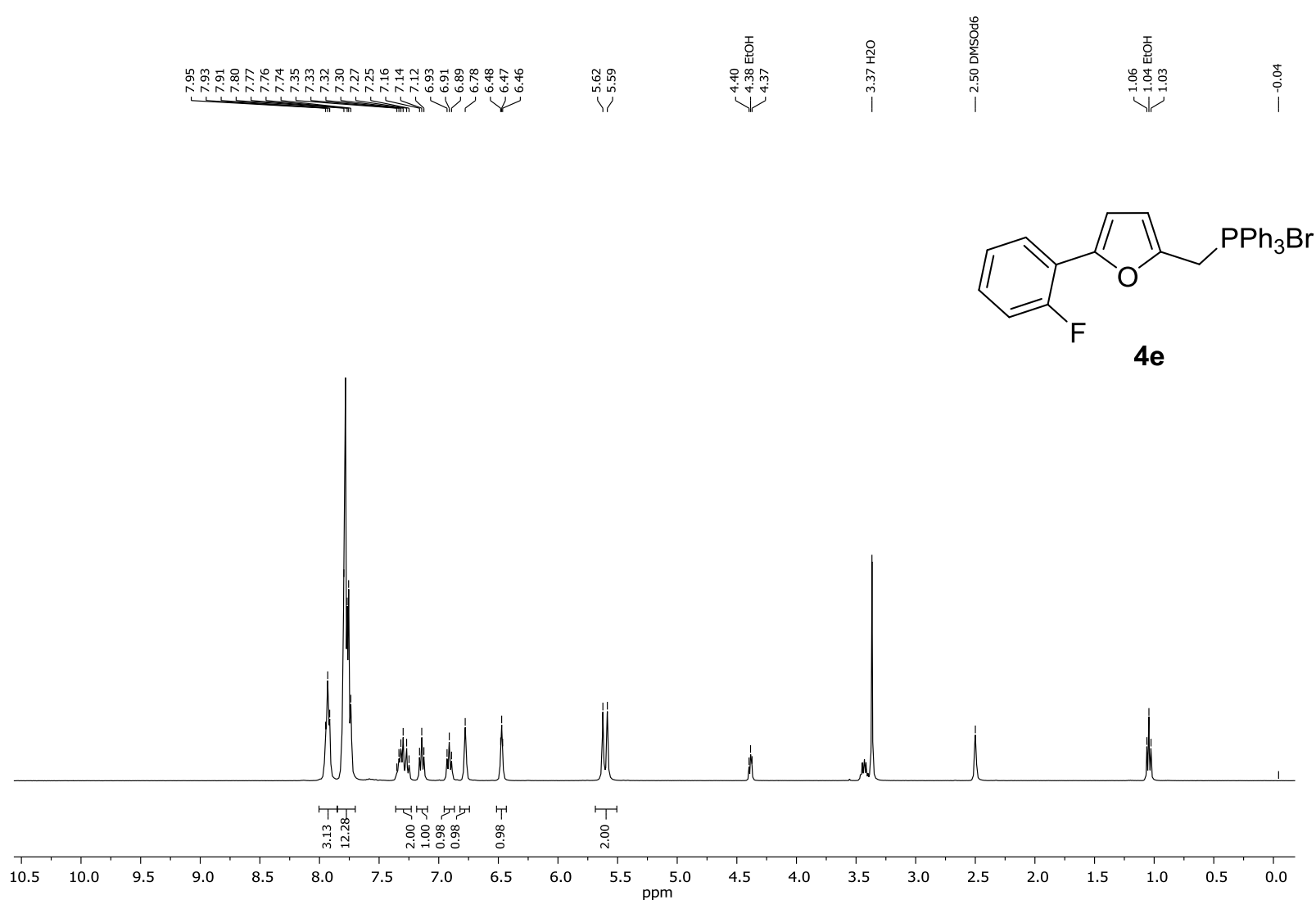

4e, ${ }^{13} \mathrm{C}\left\{{ }^{1} \mathrm{H}\right\}$ NMR (100 MHz, DMSO)

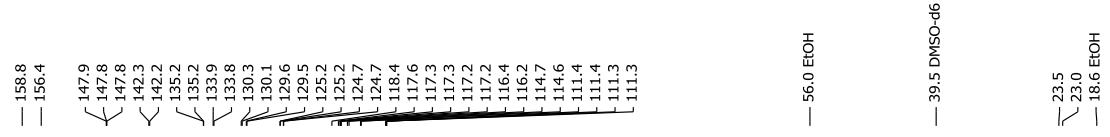

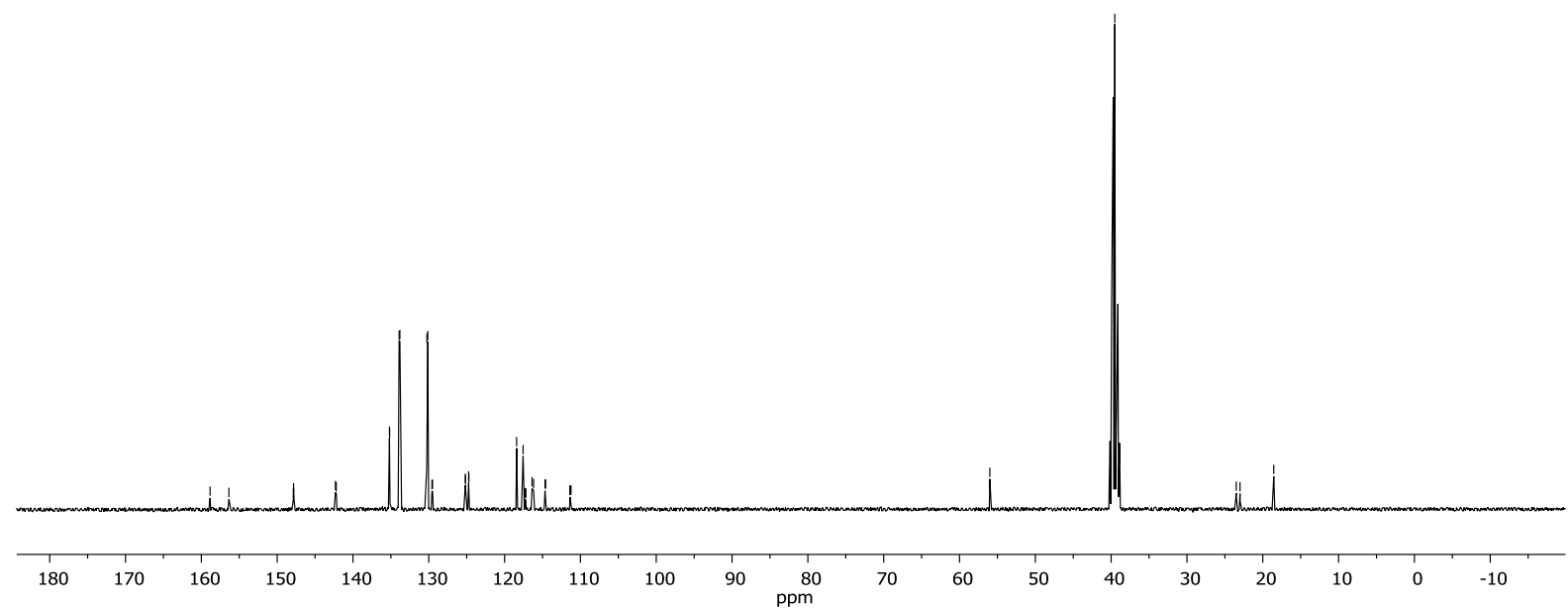


4f, ${ }^{1} \mathrm{H}$ NMR (400 MHz, DMSO)

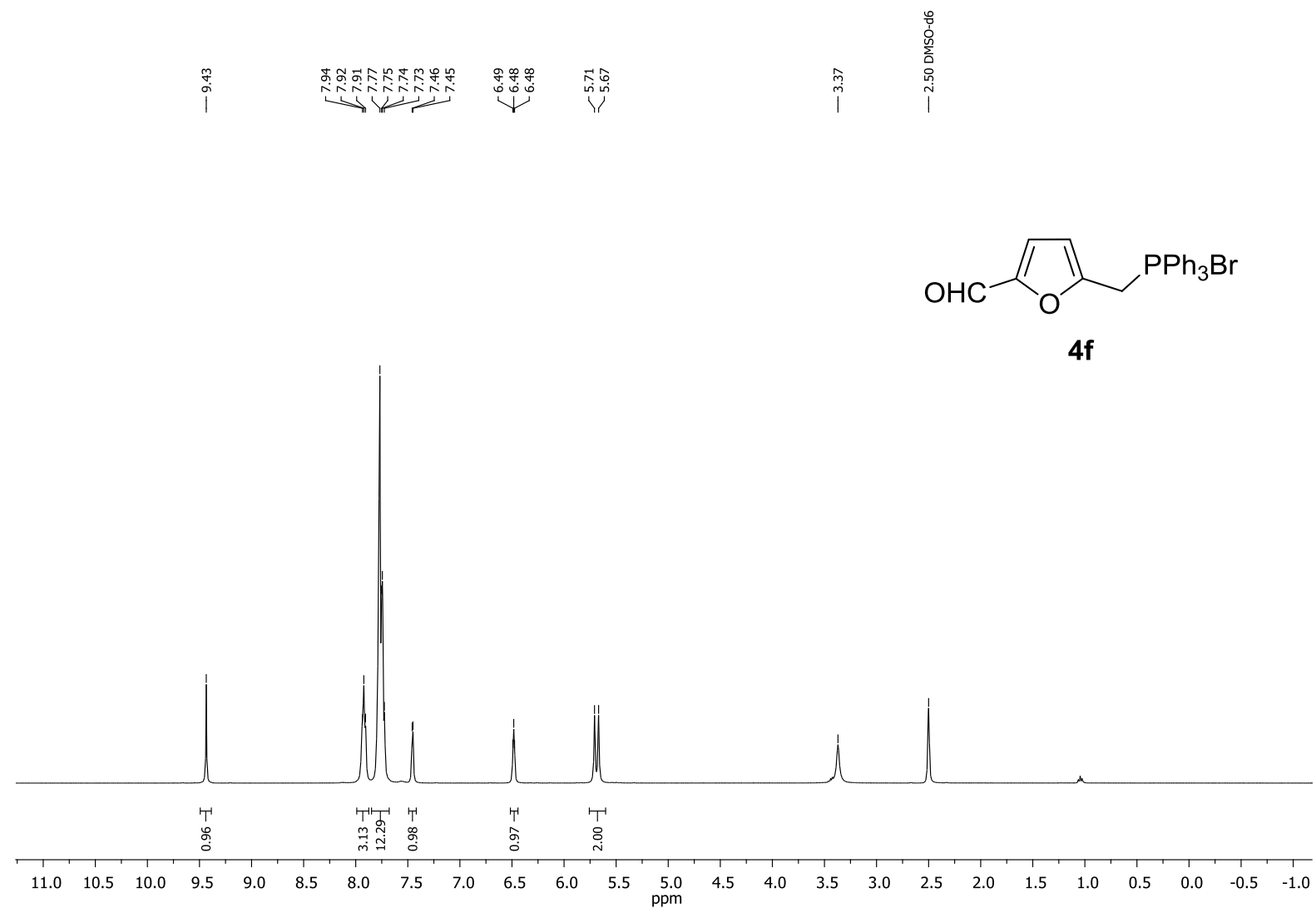

4f, ${ }^{13} \mathrm{C}\left\{{ }^{1} \mathrm{H}\right\}$ NMR (100 MHz, DMSO)

每
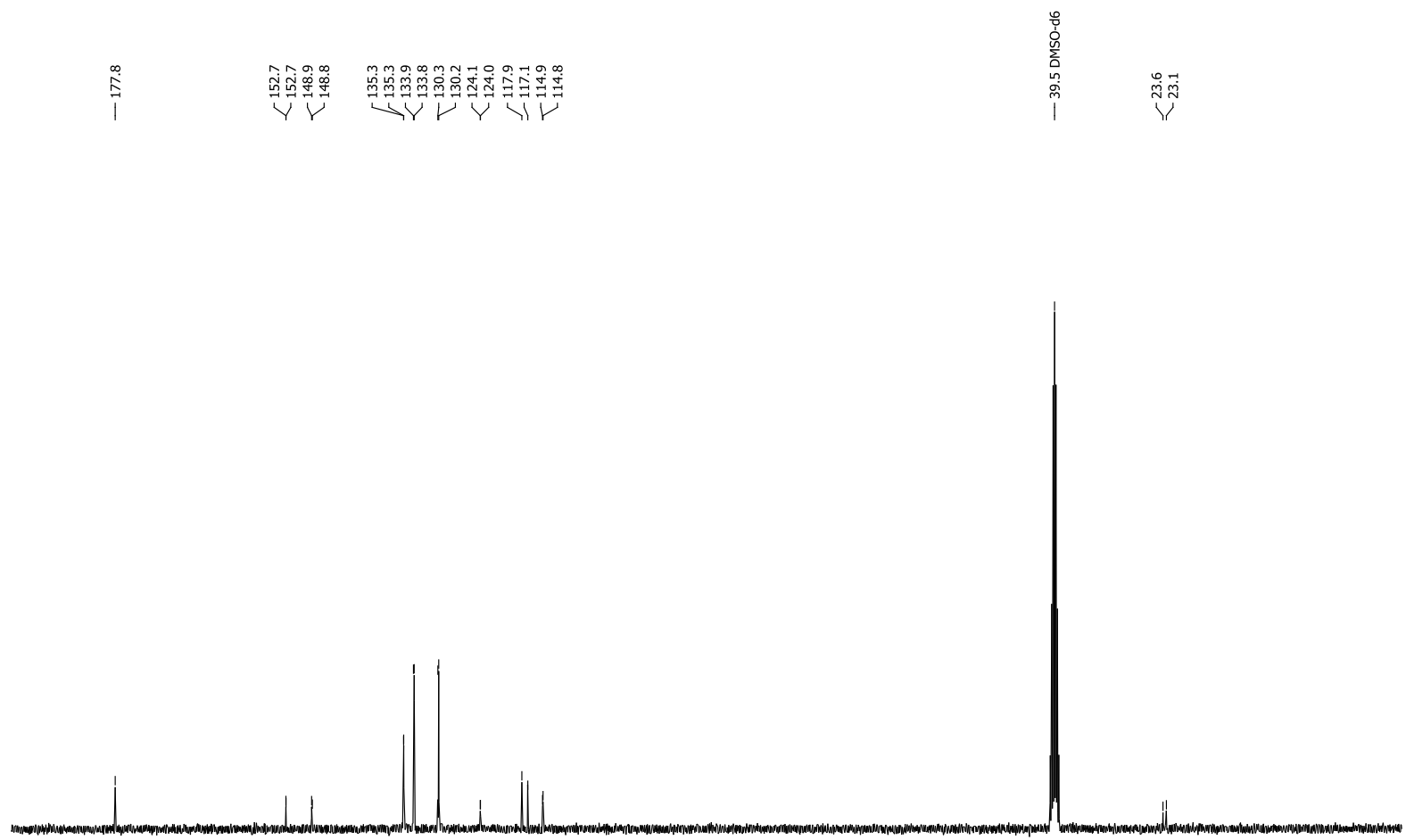

$\begin{array}{rllllllllllllllllllllll}190 & 180 & 170 & 160 & 150 & 140 & 130 & 120 & 110 & 100 & 90 & 80 & 70 & 60 & 50 & 40 & 30 & 20 & 10 & 0 & -10\end{array}$ 
4g, ${ }^{1} \mathrm{H}$ NMR (400 MHz, DMSO)
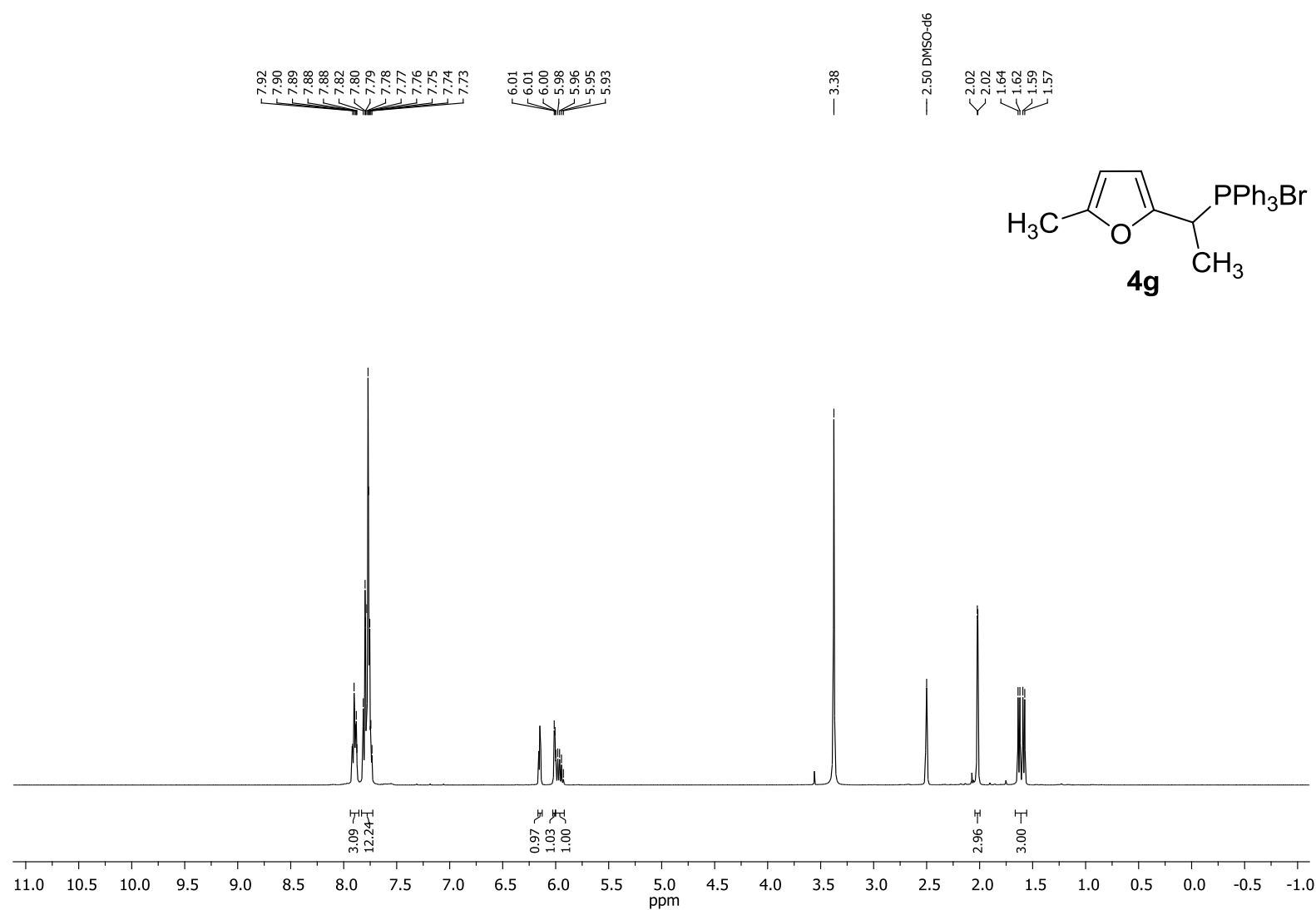

4g, ${ }^{13} \mathrm{C}\left\{{ }^{1} \mathrm{H}\right\}$ NMR $(100 \mathrm{MHz}, \mathrm{DMSO})$

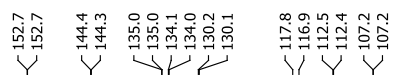
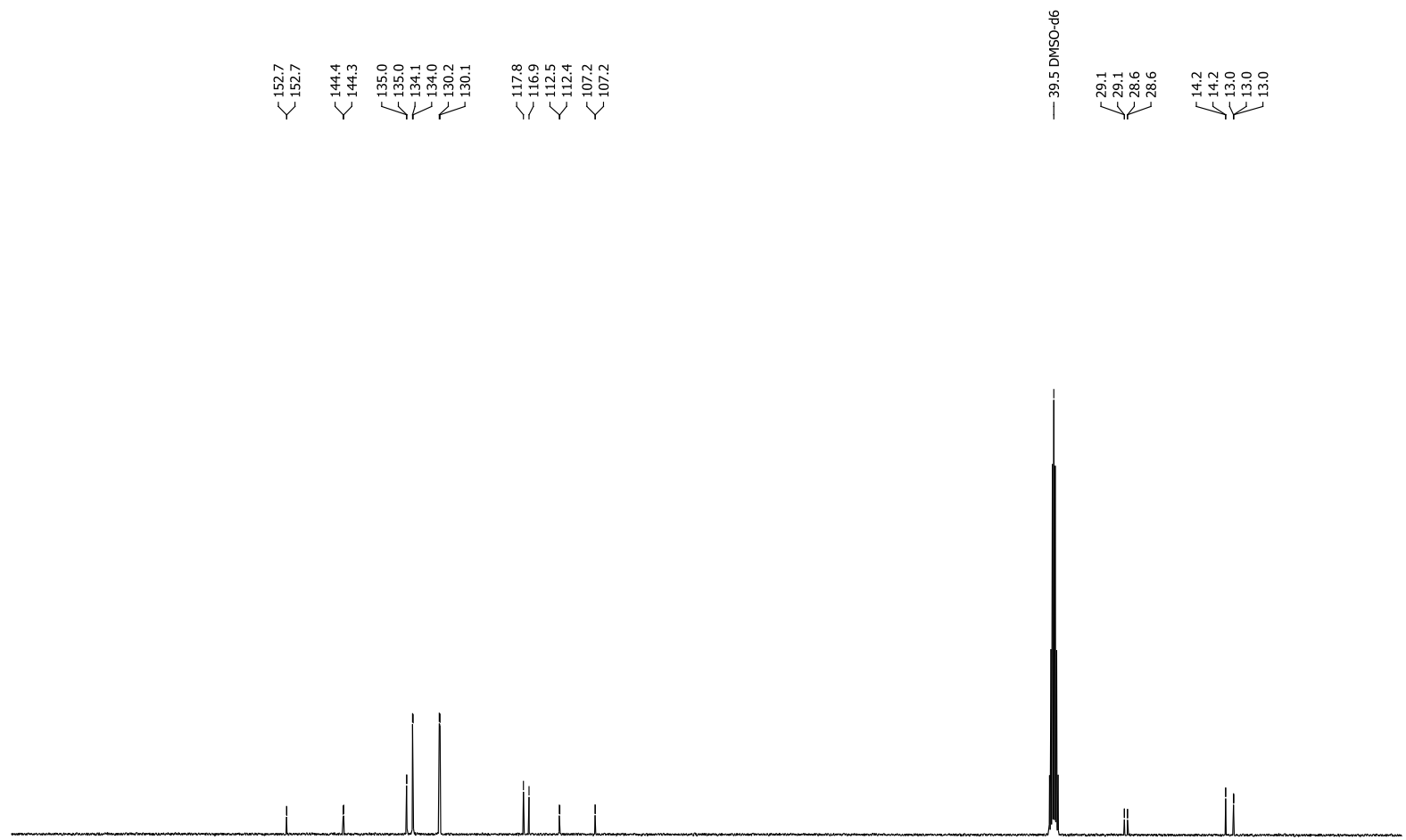

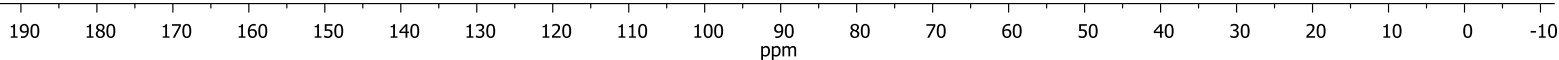


4h, ${ }^{1} \mathrm{H}$ NMR (400 MHz, DMSO)

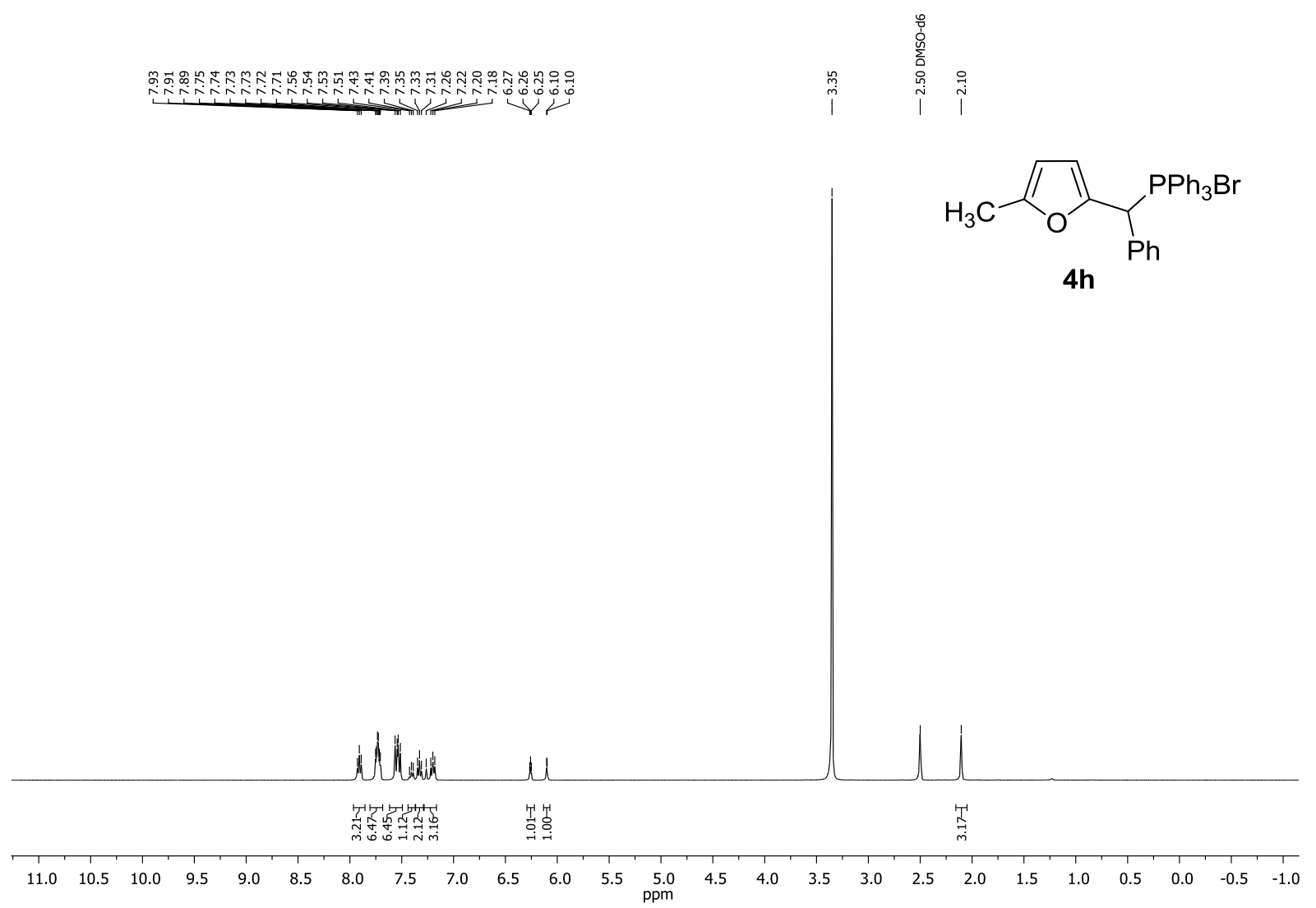

4h, ${ }^{13} \mathrm{C}\left\{{ }^{1} \mathrm{H}\right\}$ NMR (100 MHz, DMSO)

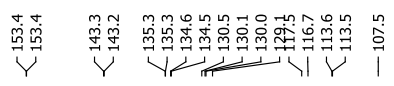
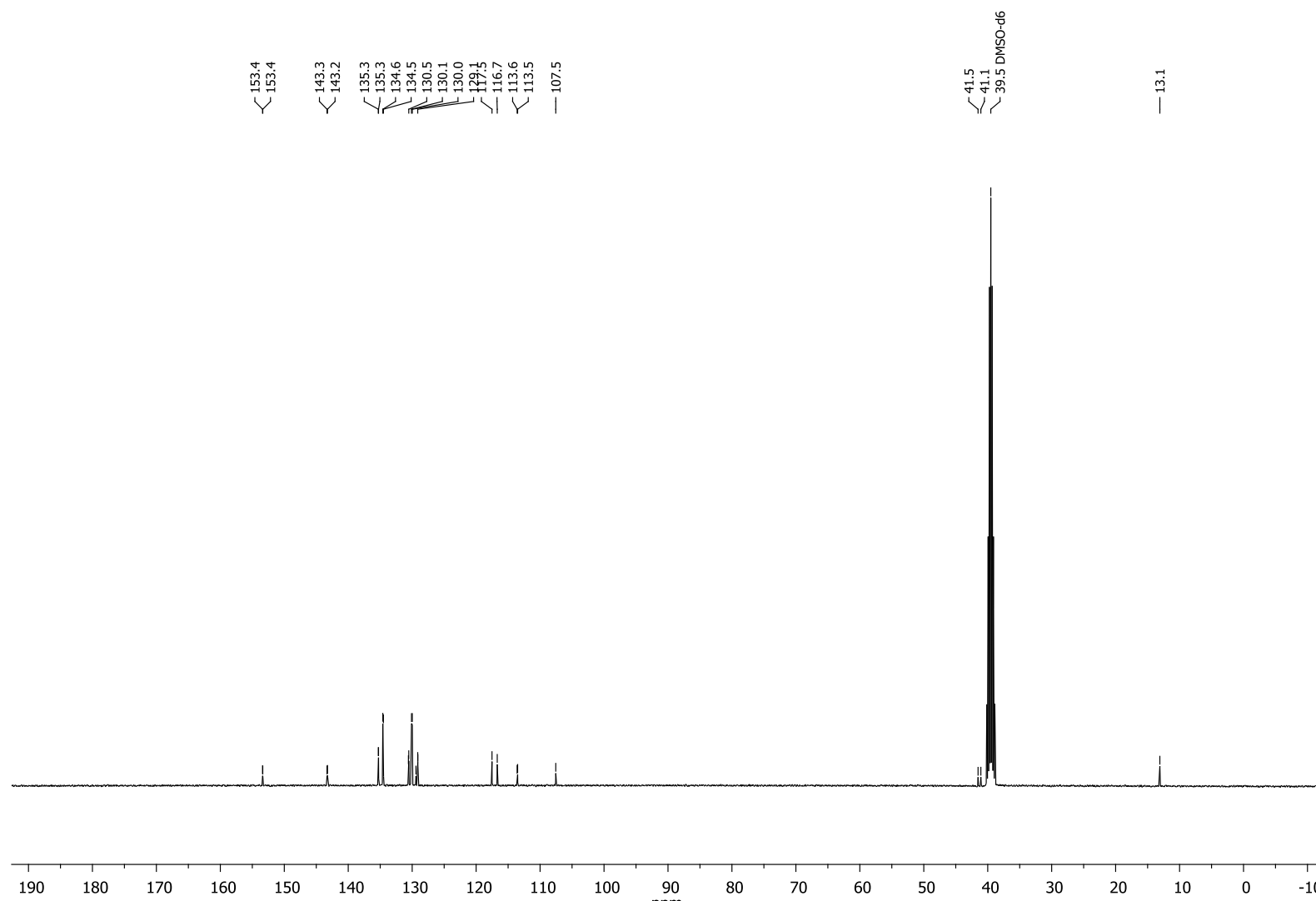
4i, ${ }^{1} \mathrm{H}$ NMR (400 MHz, DMSO)

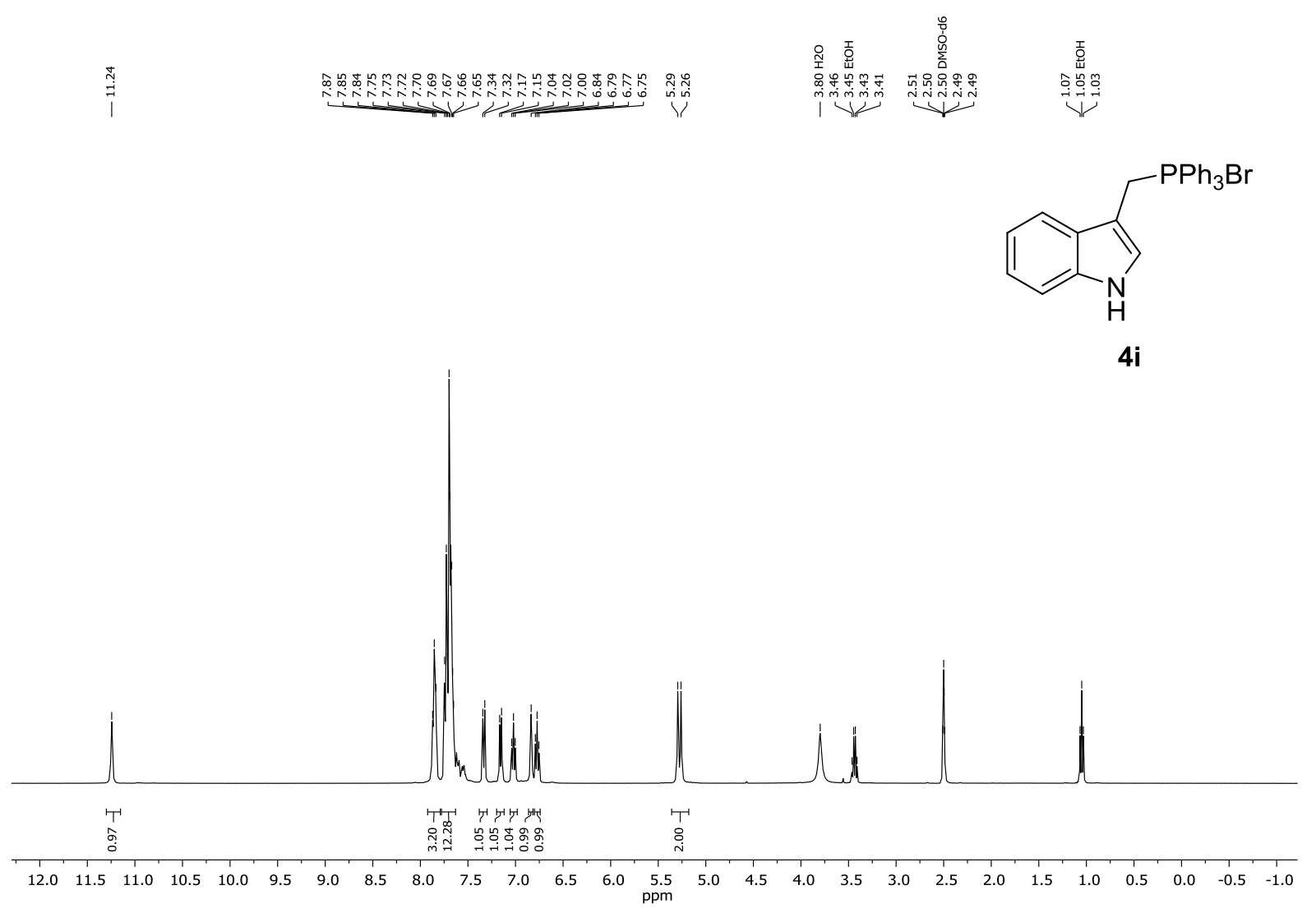

4i, ${ }^{13} \mathrm{C}\left\{{ }^{1} \mathrm{H}\right\}$ NMR (100 MHz, DMSO)

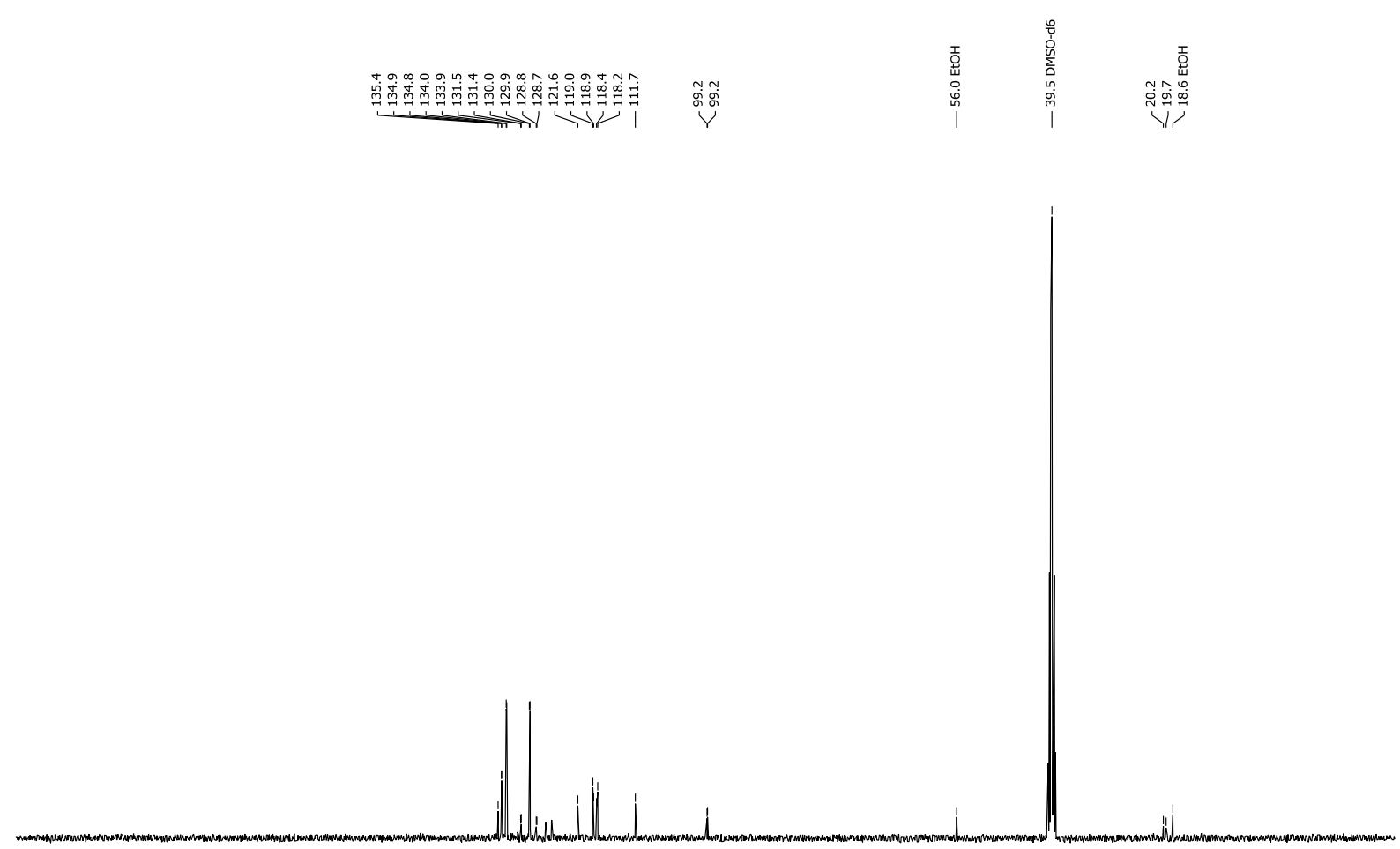

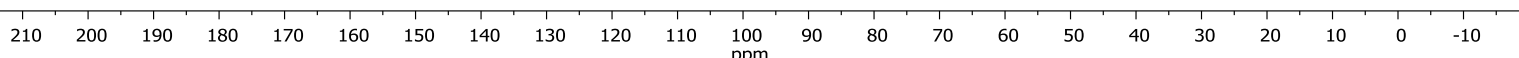


4j, ${ }^{1} \mathrm{H}$ NMR (400 MHz, DMSO)

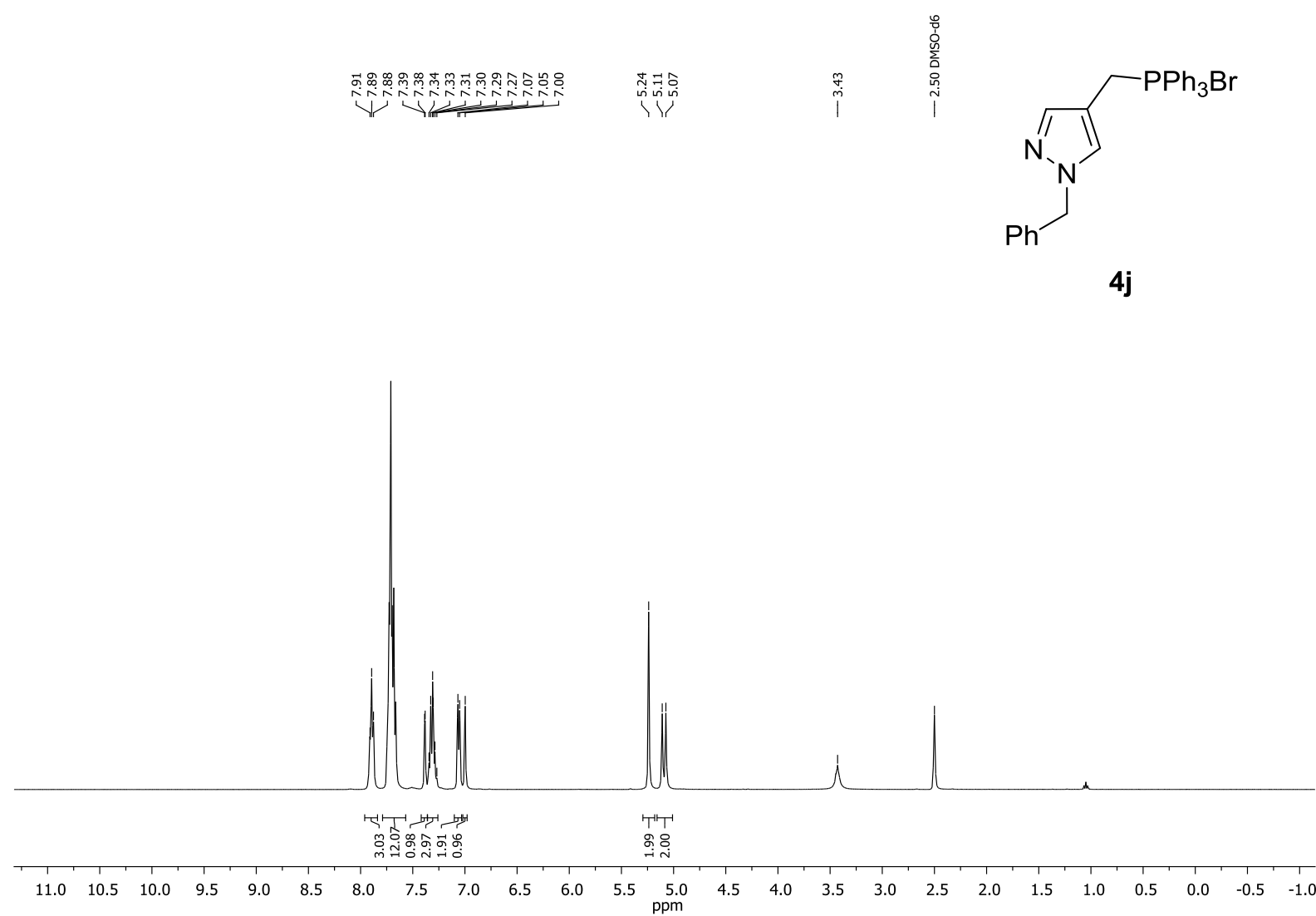

4j, ${ }^{13} \mathrm{C}\left\{{ }^{1} \mathrm{H}\right\}$ NMR (100 MHz, DMSO)

\begin{tabular}{|c|c|}
\hline 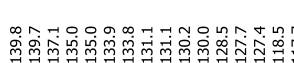 & 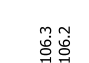 \\
\hline
\end{tabular}

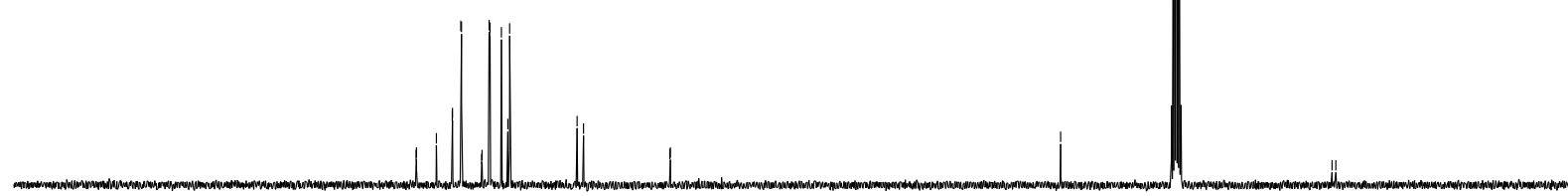

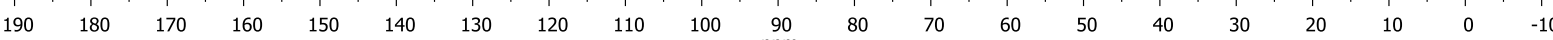


4k, ${ }^{1} \mathrm{H}$ NMR (400 MHz, DMSO)

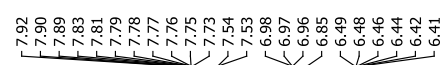

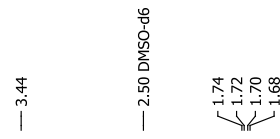
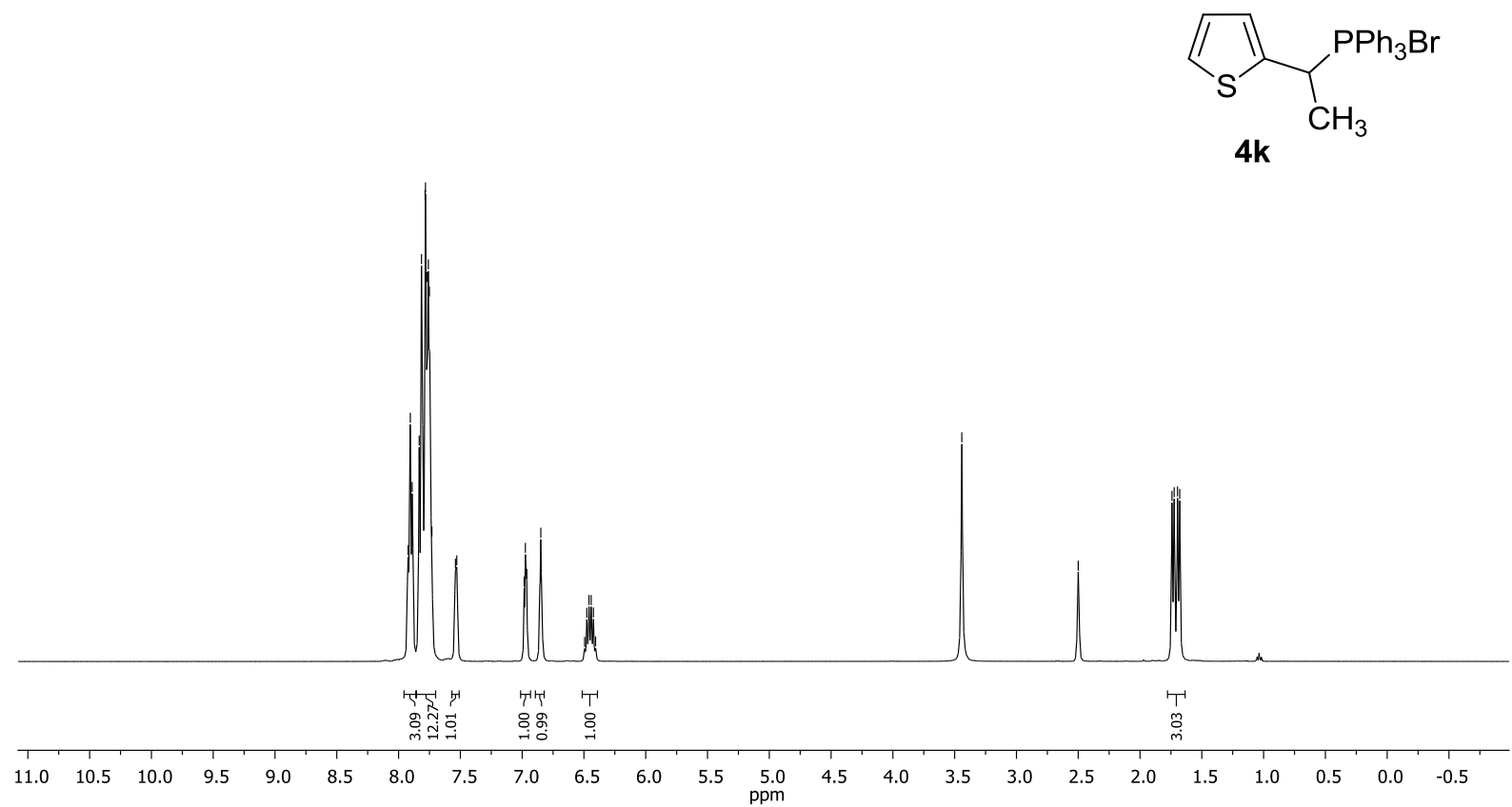

4k, ${ }^{13} \mathrm{C}\left\{{ }^{1} \mathrm{H}\right\}$ NMR (100 MHz, DMSO)

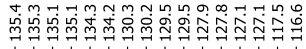
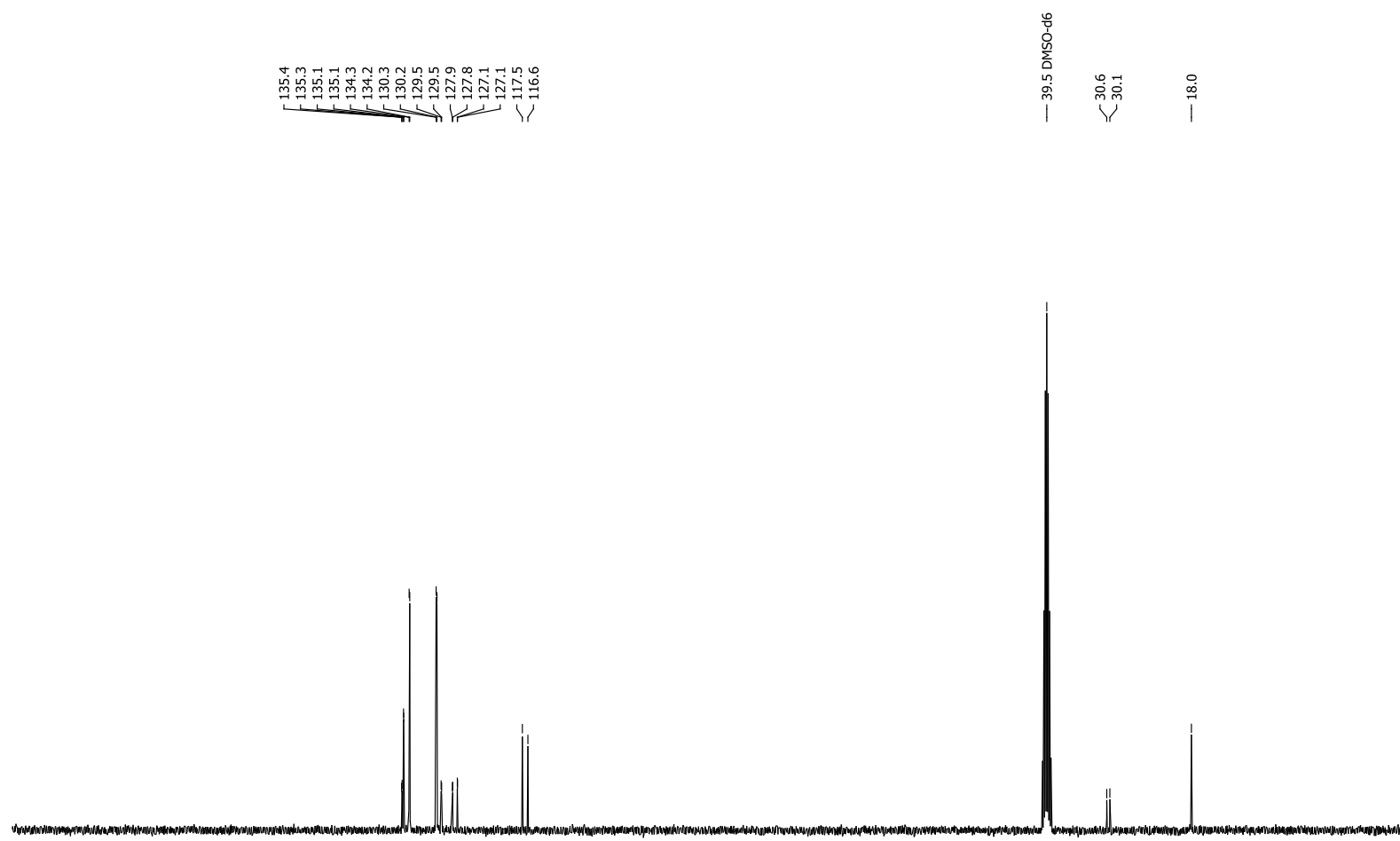

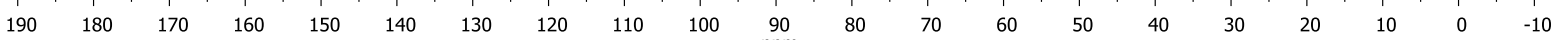


5a, ${ }^{1} \mathrm{H}$ NMR (400 MHz, DMSO)

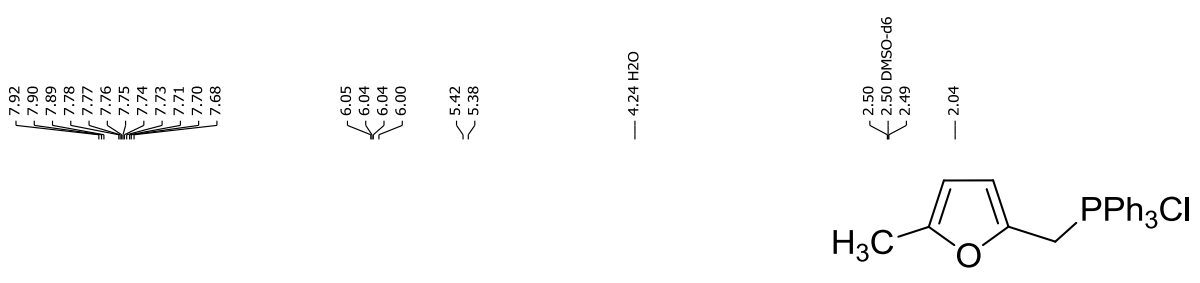

$5 a$

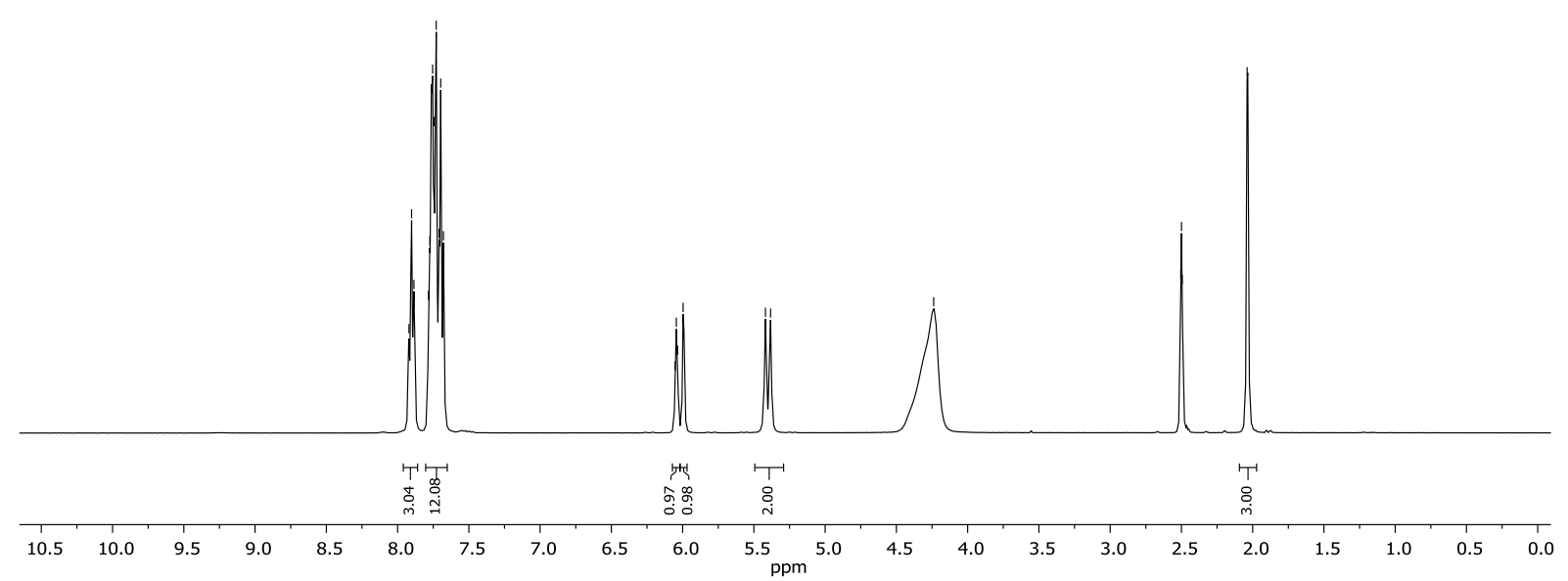

5a, ${ }^{13} \mathrm{C}\left\{{ }^{1} \mathrm{H}\right\}$ NMR (100 MHz, DMSO)
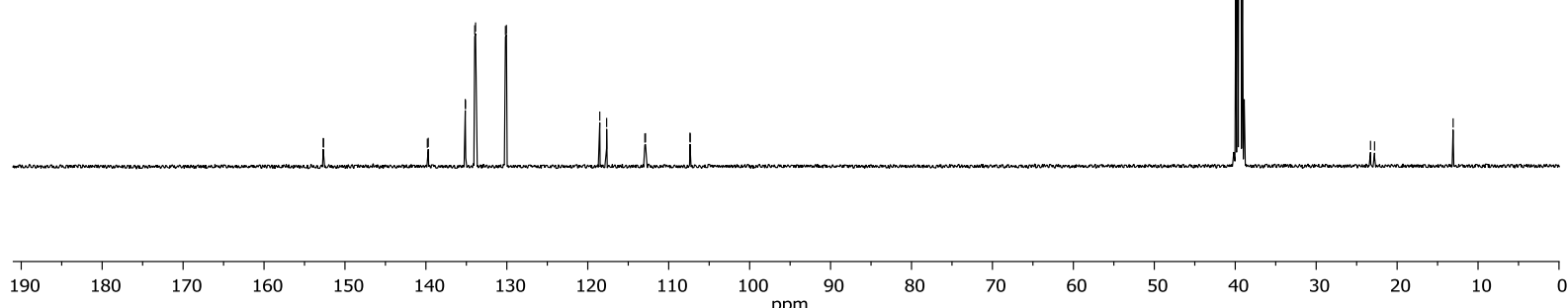
5b, ${ }^{1} \mathrm{H}$ NMR (400 MHz, DMSO)
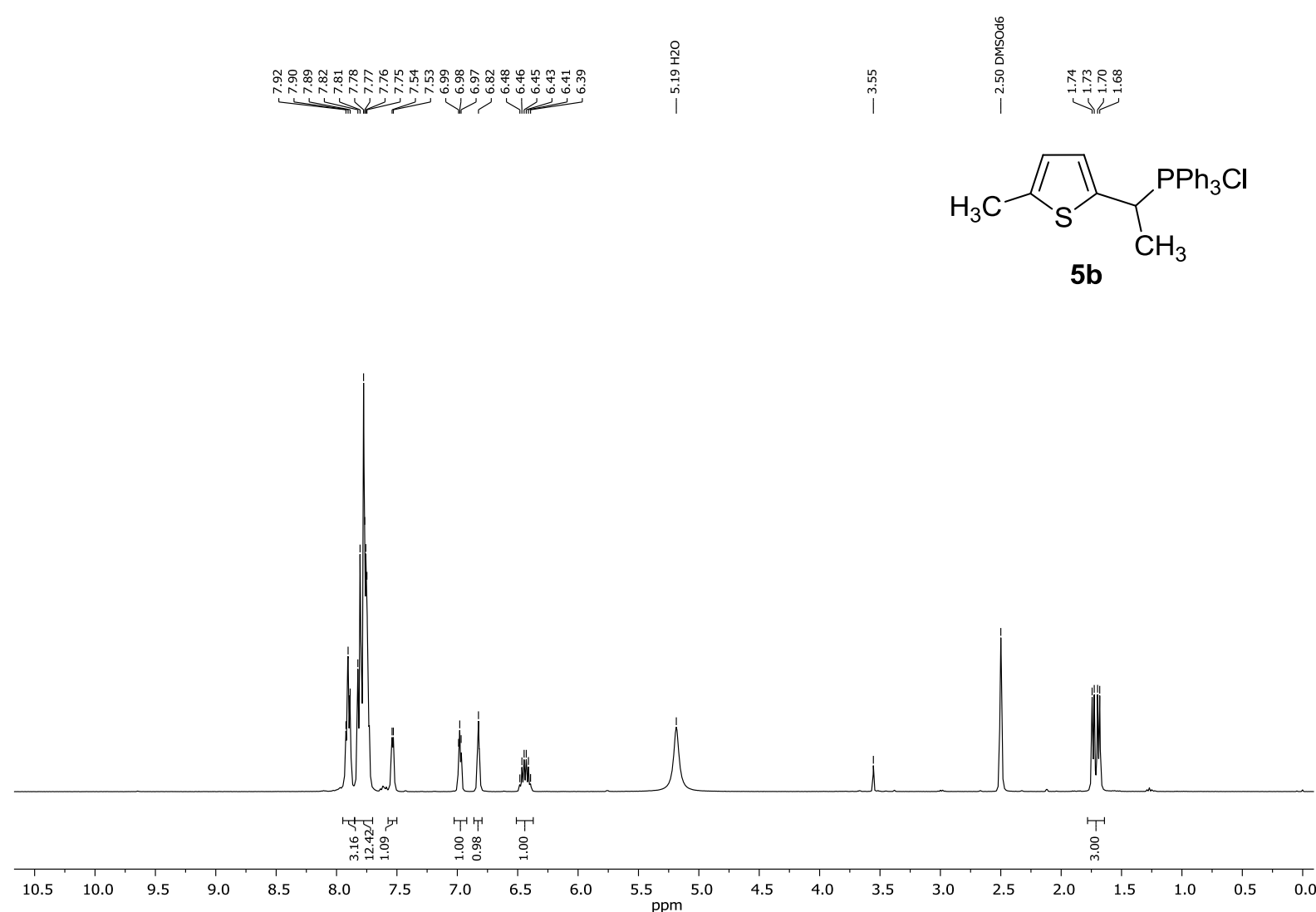

5b, ${ }^{13} \mathrm{C}\left\{{ }^{1} \mathrm{H}\right\}$ NMR (100 MHz, DMSO)

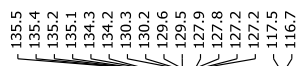
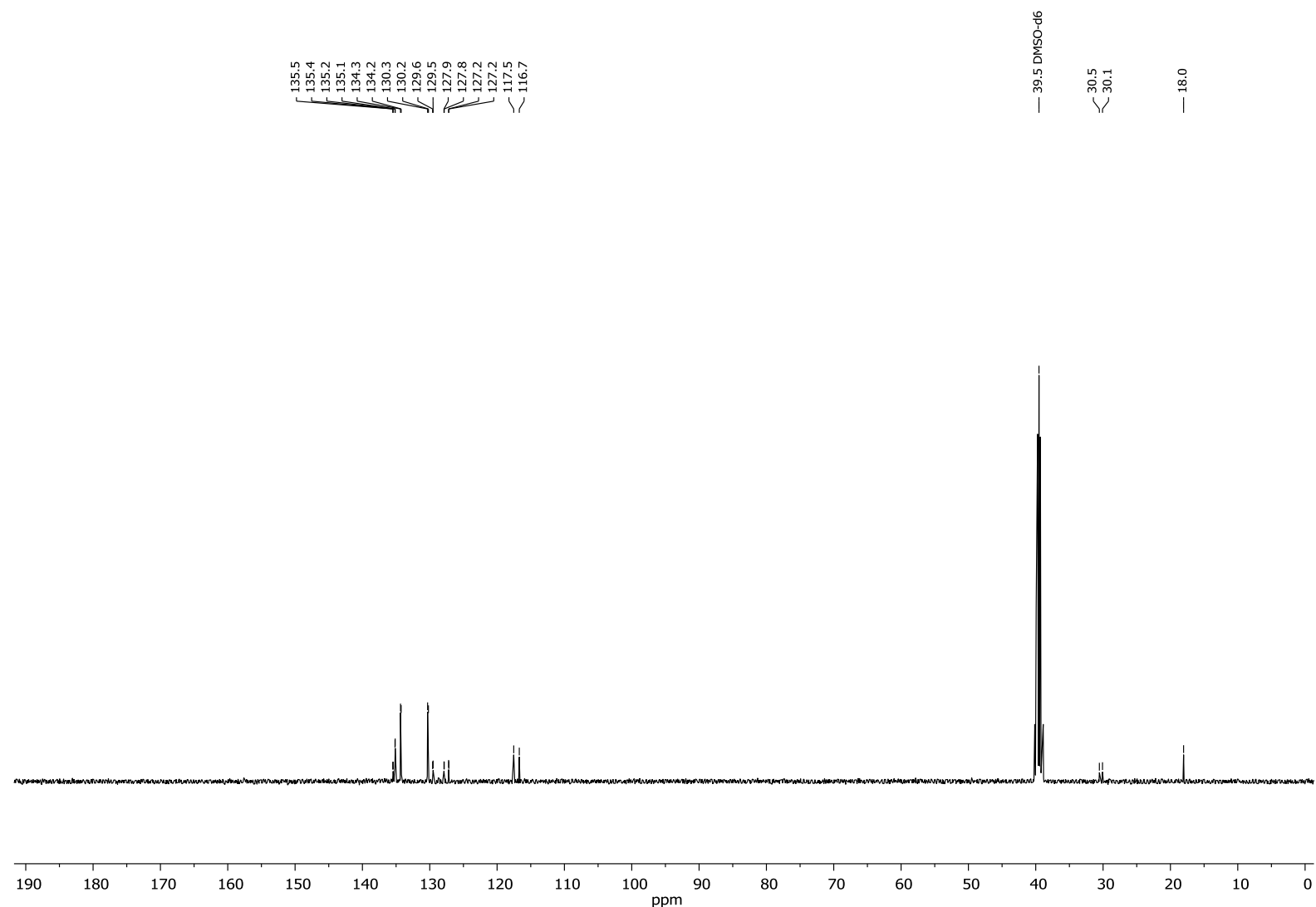
6a, ${ }^{1} \mathrm{H}$ NMR $\left(400 \mathrm{MHz}, \mathrm{CDCl}_{3}\right)$

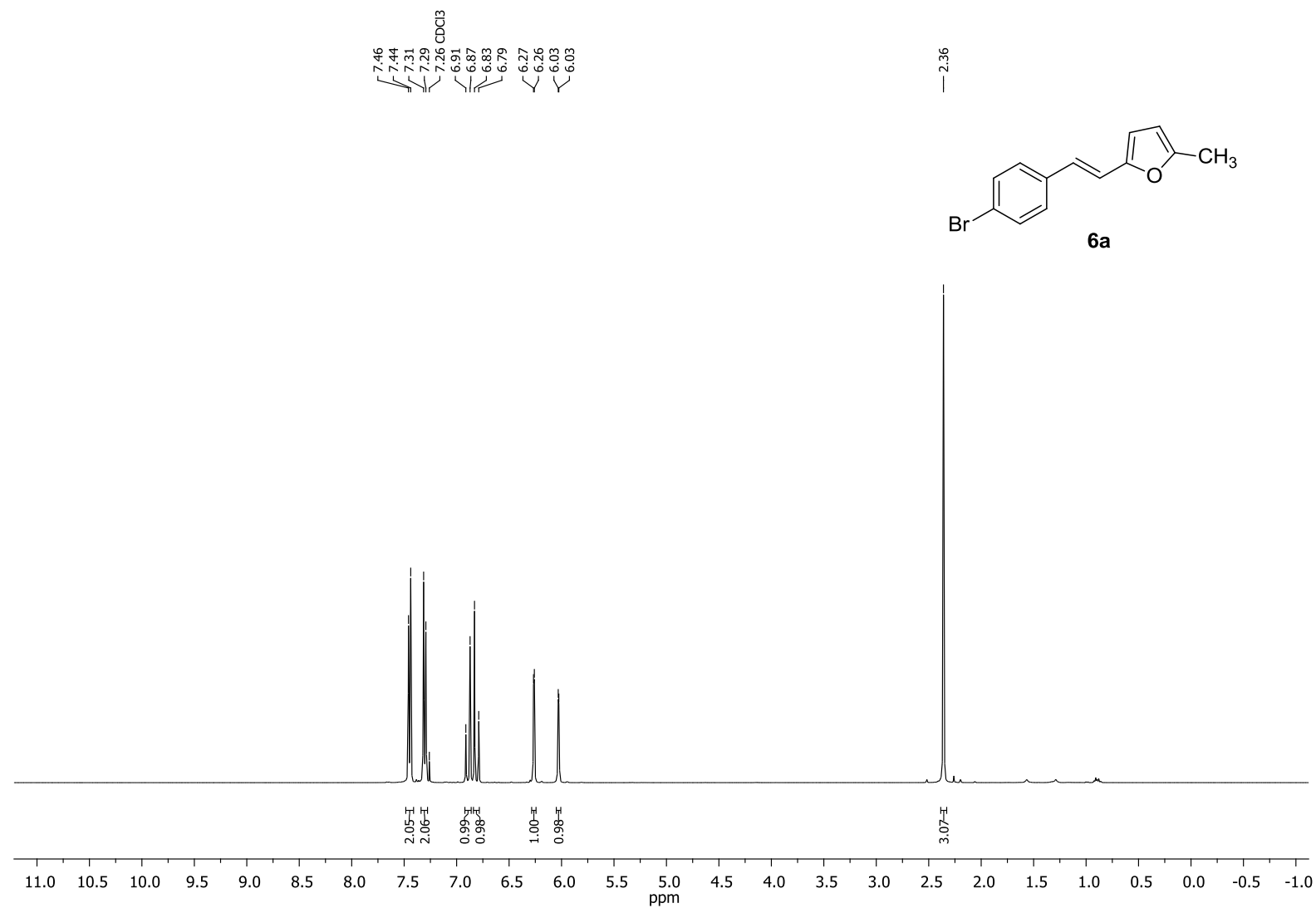

6a, ${ }^{13} \mathrm{C}\left\{{ }^{1} \mathrm{H}\right\}$ NMR $\left(100 \mathrm{MHz}, \mathrm{CDCl}_{3}\right)$
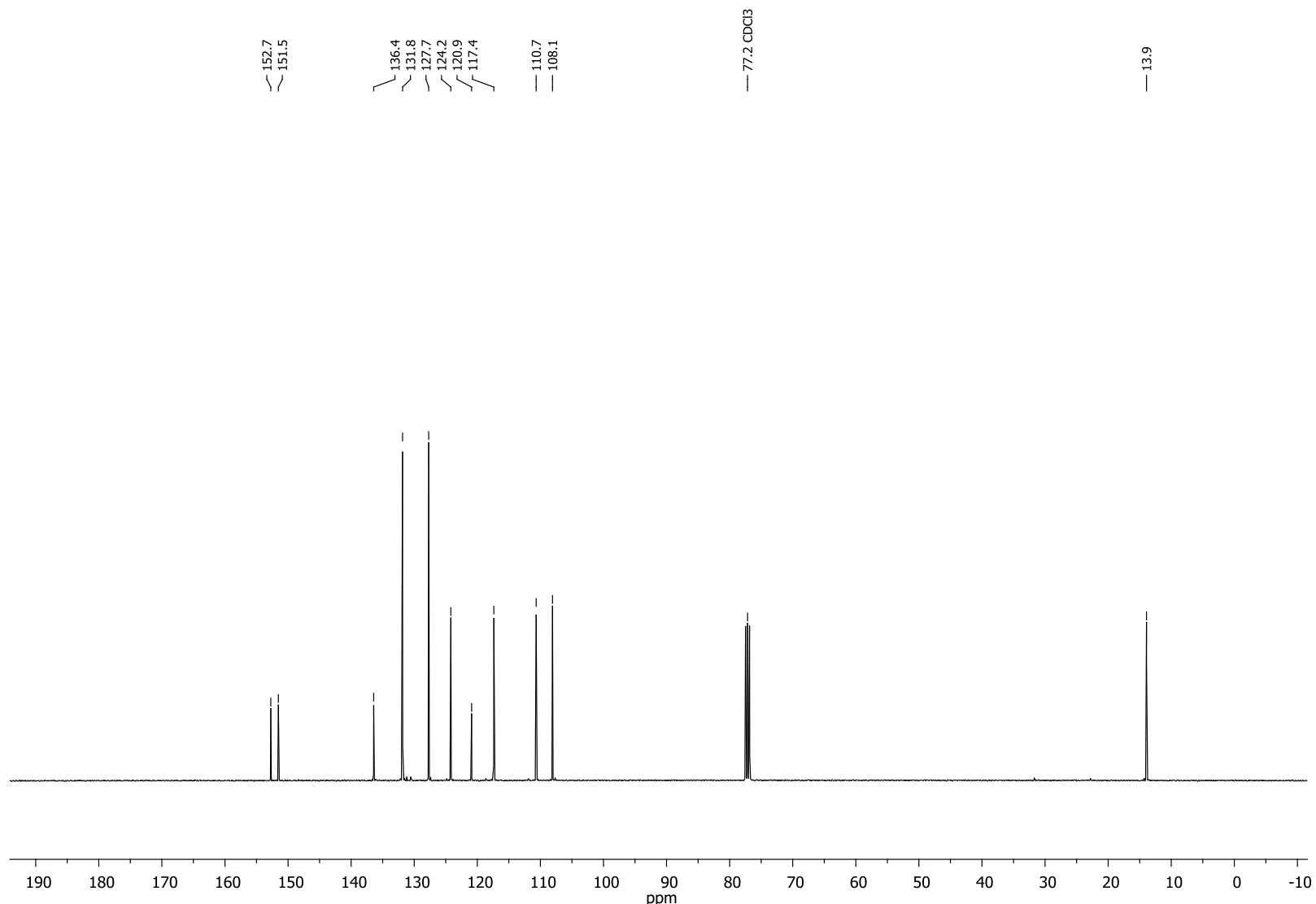
6b, ${ }^{1} \mathrm{H}$ NMR $\left(400 \mathrm{MHz}, \mathrm{CDCl}_{3}\right)$

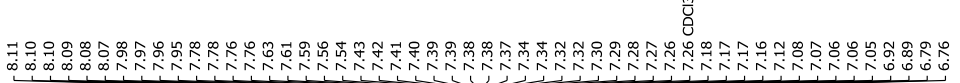

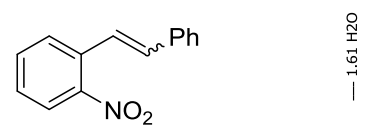

6b

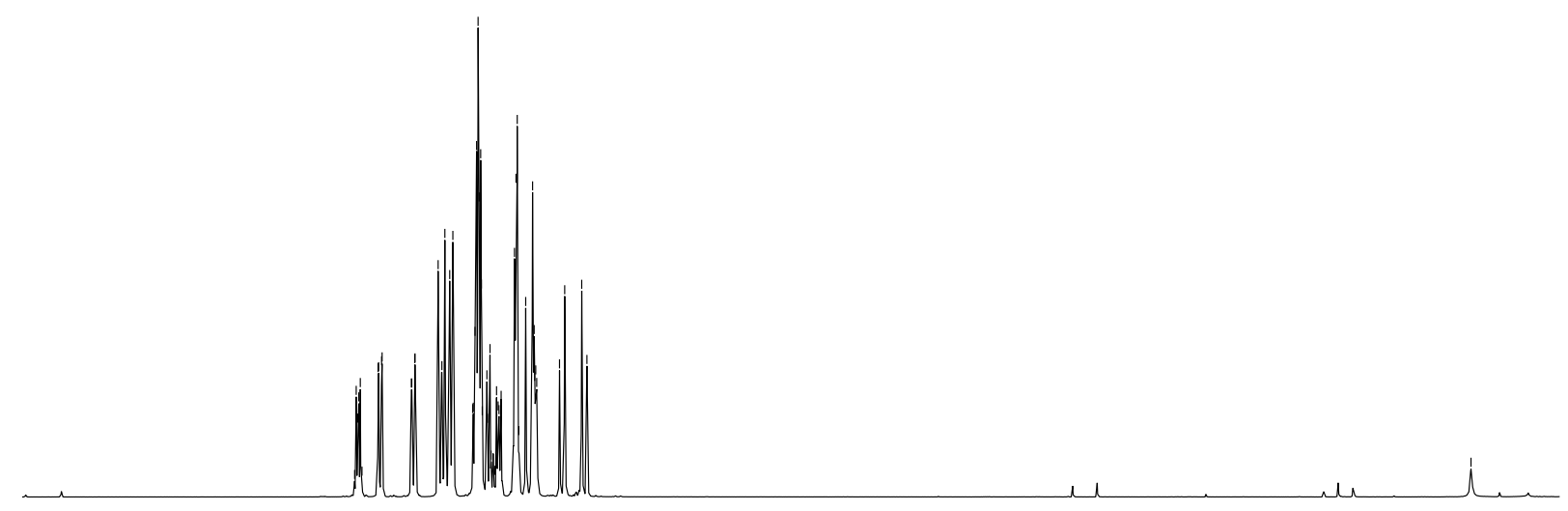

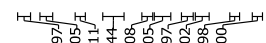

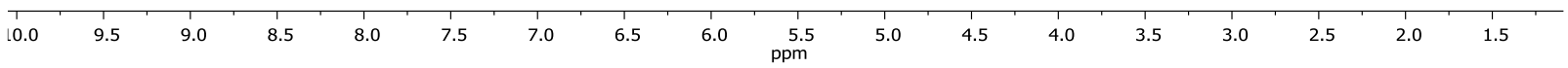

6b, ${ }^{13} \mathrm{C}\left\{{ }^{1} \mathrm{H}\right\}$ NMR $\left(100 \mathrm{MHz}, \mathrm{CDCl}_{3}\right)$

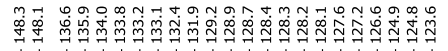

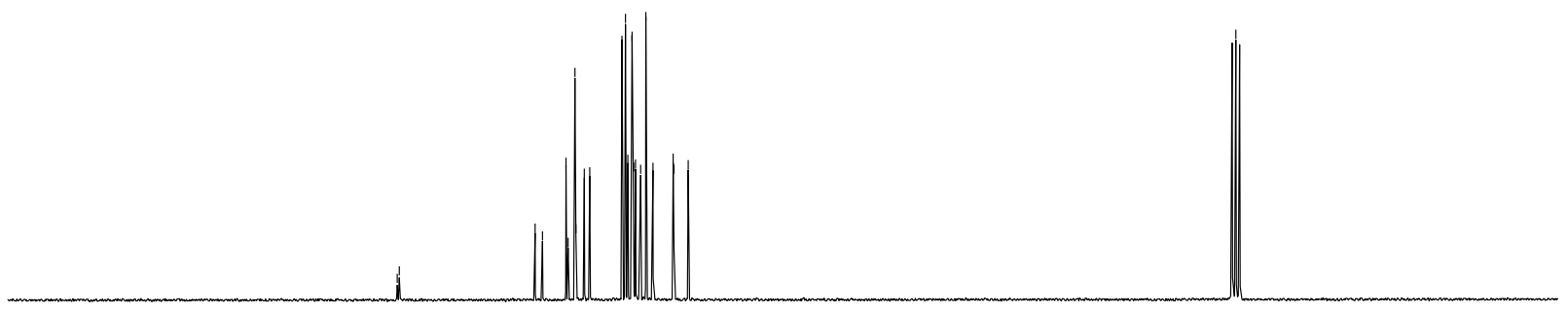

$\begin{array}{llllllllllllllllllllllllllllllllllllll}180 & 175 & 170 & 165 & 160 & 155 & 150 & 145 & 140 & 135 & 130 & 125 & 120 & 115 & 110 & 105 & 100 & 95 & 90 & 85 & 80 & 75 & 70 & 65 & 60 & 55 & 5\end{array}$ 
6c, ${ }^{1} \mathrm{H}$ NMR $\left(400 \mathrm{MHz}, \mathrm{CDCl}_{3}\right)$
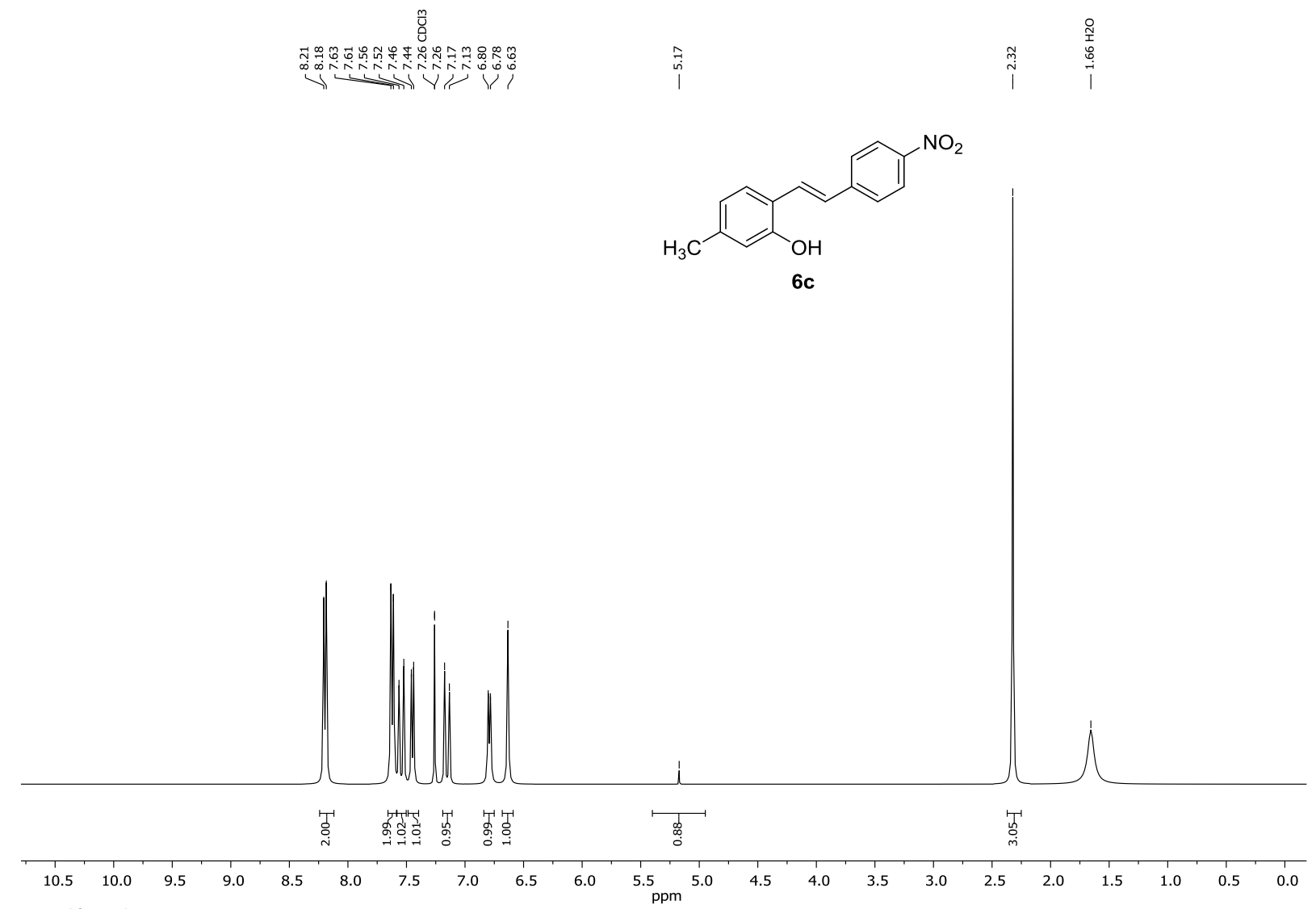

6c, ${ }^{13} \mathrm{C}\left\{{ }^{1} \mathrm{H}\right\}$ NMR $\left(100 \mathrm{MHz}, \mathrm{CDCl}_{3}\right)$

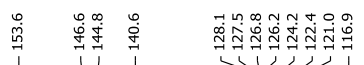
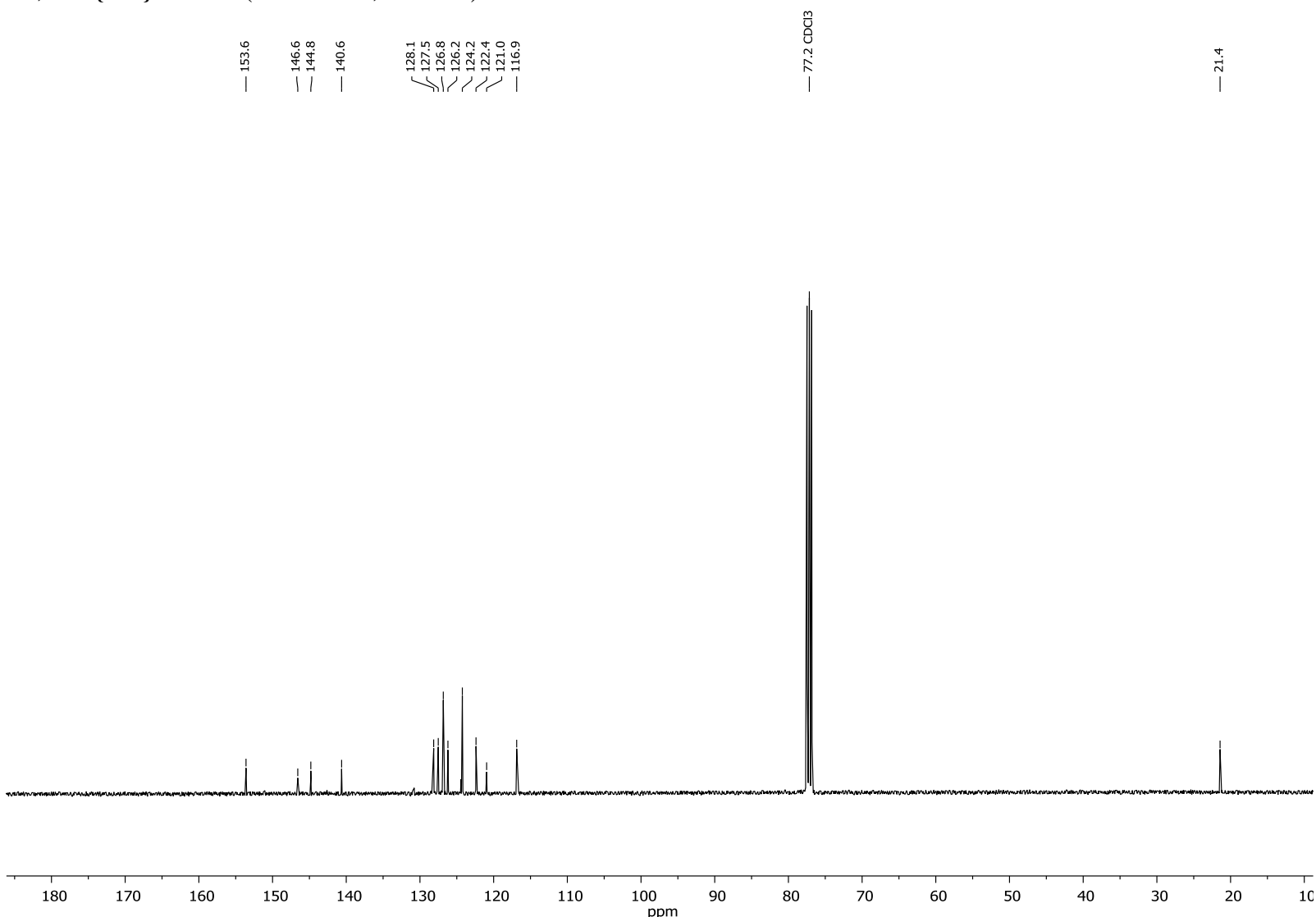